\title{
Spatiotemporal dynamics and modelling support the case for area-wide management of citrus greasy spot in a Brazilian smallholder farming region
}

3 F.F. Laranjeira ${ }^{a^{*}}$, S.X.B. Silva ${ }^{\text {b }}$, R.E. Murray-Watson ${ }^{c}$, A.C.F. Soares ${ }^{\text {d }}$, H.P.Santos-Filho ${ }^{a}$, 4 N.J. Cunniffe ${ }^{c}$

5 a Embrapa Cassava \& Fruits, CP 007, Cruz das Almas, Bahia, Brazil, CEP 44380-000.

6 b Agência Estadual de Defesa Agropecuária da Bahia (ADAB), Salvador, Bahia, Brazil.

$7 \quad{ }^{\mathrm{c}}$ Department of Plant Sciences, University of Cambridge, Downing Street, Cambridge, UK CB2 3EA.

8 d Núcleo de Estudos em Microbiologia Aplicada, Universidade Federal do Recôncavo da Bahia (UFRB), Cruz

9 das Almas, Brazil.

10 *E-mail address: francisco.laranjeira@embrapa.br

11 Running head: Citrus greasy spot in Brazil

13 Keywords: Citrus sinensis, Zasmidium citri, primary and secondary infection, disease epidemiology, mathematical model, meta-population model.

\section{Abstract}

Citrus greasy spot (CGS), caused by Zasmidium citri, induces premature defoliation and yield loss in Citrus spp. CGS epidemiology is well understood in areas of high humidity such as Florida (USA), but remains unaddressed in Brazil, despite differing climatic conditions and disease management practices. We characterize the spatiotemporal dynamics of CGS in the Recôncavo of Bahia, Brazil, focusing on four hierarchical levels (quadrant, plant, grove and region). A survey conducted in 19 municipalities showed that disease is found throughout the entire region with a prevalence (i.e. proportion of affected sampling units) of $100 \%$ in groves and plants, and never lower than $70 \%$ on leaves. Index of dispersion $(D)$ values suggest the spatial pattern of symptomatic units lies somewhere between random and regular. This was confirmed by the parameters of the binary power law for plants and their quadrants $(\log (A)<0$ and $b<1)$. Variability in disease severity at different plant heights $(0.7 \mathrm{~m}, 1.3 \mathrm{~m}$ and $2.0 \mathrm{~m})$ was tested, but no consistent differences were observed. We introduce a simple compartmental model synthesising the epidemiology of the disease, in order to motivate and guide further research. The data we have collected allow such a model to be parameterised, albeit with some ambiguity over the proportion of new infections that result from inoculum produced within the grove vs. external sources of infection. By extending our model to include two populations of growers - those who control and those who do not - coupled by the spread of airborne inoculum, we investigate likely performance of the type of cultural controls that would be accessible to citrus growers in Northeastern Brazil. Our model shows that control via removal of the key source of inoculum - i.e. fallen leaves - can be very effective. However, successful control is likely to require area-wide strategies, in which a

38 large proportion of growers actively manage disease. 


\section{Introduction}

Citrus greasy spot (Zasmidium citri Whiteside), CGS, is considered an important fungal disease in areas of high relative air humidity and temperature (Mondal and Timmer, 2006; Silva et al., 2015; Timmer \& Gottwald, 2000; Whiteside, 1988), such as the Caribbean basin and Florida in the USA. The main symptom is irregular leaf spots resembling a brownish-black grease, surrounded by a greenish-yellow halo which is more conspicuous in the disease's initial stages (Hidalgo et al., 1997). Dark spots - which are leaf symptoms rather than perithecia - are visible on the abaxial side of the leaf and usually correspond to chlorotic areas on the adaxial side. The former increase in size whereas the latter fade away (Timmer \& Gottwald, 2000; Whiteside, 1988). Z. citri also infects fruits causing unsightly rind blemishing which can affect trade value (Timmer \& Gottwald, 2000). Perithecia are produced only in fallen decomposing leaves (Timmer et al., 2000). CGS leads to premature defoliation followed by reduction of both fruit size and plant vigour (Timmer et al., 2000). At least in Cuba, associated loss of yield can reach 5 t/ha (Diaz et al, 1985).

Despite its importance in many citrus producing regions (Timmer et al., 2000), CGS is considered to be only a minor disease in Brazil. Few studies characterizing its epidemiology in the Brazilian context have therefore been performed (Laranjeira et al., 2005). However, CGS is important in Bahia State, the second most important citrus growing region in Brazil. A regional survey in Bahia showed that the disease occurs at high prevalence $(100 \%$ of the sampled groves) meaning CGS is endemic, in the sense of being regularly found and very common in the area (Silva et al., 2009). Moreover, CGS has been shown to exert a severe defoliating effect on cultivated citrus in Bahia, with one study estimating that 500 leaves are lost due to the disease per year from each infected "Pera" sweet orange plant (Silva et al., 2015). Surprisingly, however, our discussions with citrus growers in Bahia reveal they do not perceive CGS to be a yield-limiting factor, and recent reports indicate that less than $4 \%$ of growers try to manage the disease (Rodrigues, 2018).

Studies based on the spatiotemporal patterns of the disease may help to better understand the pathogen's dispersion mechanism(s) and to develop additional strategies for disease management. In particular, understanding spatial patterns of disease offers the promise of understanding the balance between auto- and allo-infection at the grove scale, and in turn of revealing the extent to which disease control must be attempted on an area-wide basis. The association of the life-cycle with weather is well studied (Garcia et al., 1980; Hidalgo et al., 1997; Mondal \& Timmer, 2003a) but there are no reports regarding spatial patterns.

In Cuba, rain and relative air humidity are correlated with CGS incidence. The disease builds up between summer and early autumn, when the most intense rains occur and the relative humidity increases to between $84 \%$ and $90 \%$ (Garcia et al., 1980). In Costa Rica ascospore release closely follows seasonal rain patterns. The number of trapped ascospores quickly rises in May, peaking at the beginning of June (late spring). This is then followed by considerable decline in July and the number of released ascospores remains low for the rest of the year (Hidalgo et al., 1997). In Florida in the USA the pseudothecia grow slowly on the decomposing litter during the relatively dry spring, and ascospore release is retarded until the 
summer rains, with symptoms following only in the winter (Timmer et al., 2000). In Northeastern Brazil (Bahia), however, the weather conditions are conducive for inoculum production in all seasons. The relative humidity is always higher than $70 \%$ and rain events occur throughout the year (Silva et al., 2015).

Despite the amount of information generated, no study has attempted to construct a mathematical model of CGS. In this paper, we develop a model of Z. citri population dynamics which we use to compare the likely efficacy of disease management strategies. In Florida and other regions with an extensive citrus-production industry, cultivation tends to be based around large commercial operations, within which Z . citri is controlled by fungicides (Mondal \& Timmer, 2006a). However, small-holder growers are in the majority in Bahia, and such growers do not have ready access to expensive agrochemicals, or even to the machinery required to apply such products. We therefore concentrate here on the performance of a cultural control of the type that could potentially be performed by resource-poor growers. We focus in particular on removal of fallen leaf litter, a management strategy originally proposed by Whiteside (1970) nearly 50 years ago. Such a localised cultural control done by an individual grower can clearly only affect the component of the epidemic spread driven by within-grove production of inoculum. We therefore particularly focus on using our model to assess whether and under which conditions the performance of cultural disease management can be improved when it is taken up area-wide by a significant fraction of a community of growers (Bassanezi et al., 2013; Bergamin Filho et al., 2016; Sherman et al., 2019).

\section{Materials and Methods}

\section{Levels of the spatial hierarchy and sampling procedures}

106
We divided our sample space into four levels: plant quadrants (Hierarchical Level 1, HL1), plants in a grove (HL2), groves (HL3) and the region (HL4). A plant quadrant was considered as each side of a plant, i.e. there were two within-row quadrants and two acrossrows quadrants. A grove was defined as a uniform production unit inside a farm; groves we considered ranged in size from $1 \mathrm{Ha}$ to $3 \mathrm{Ha}$. Plants in a single grove invariably had the same rootstock and scion varieties, as well as the same age (which varied between three and six years over the set of groves we considered) and planting practice (i.e. spacing within and across rows).

To guide decisions about logistics and methods used at the other spatial levels, CGS prevalence (fraction of disease cases in a sample of a given region) and incidence (fraction of affected plants in a given orchard) were first quantified in our HL4, the 'Recôncavo da Bahia' region (an area formed of 20 munipalities in the vicinity of Todos os Santos Bay on the East coast of Brazil near the city of Salvador; see also Fig. 1). As a first criterion, only the 19 municipalities with at least 100 ha of citrus groves were sampled (IBGE, 2017): Cachoeira ( $\left.38^{\circ} 56^{\prime} 56^{\prime \prime} \mathrm{W}, 12^{\circ} 35^{\prime} 26^{\prime \prime} \mathrm{S}\right)$, Cabaceiras do Paraguaçu (39 $\left.11^{\prime} 12^{\prime \prime} \mathrm{W}, 12^{\circ} 37^{\prime} 50^{\prime \prime} \mathrm{S}\right)$, Castro Alves ( $\left.39^{\circ} 14^{\prime} 45^{\prime \prime} \mathrm{W}, 12^{\circ} 41^{\prime} 32 " \mathrm{~S}\right)$, Conceição da Feira (38 58' 31"W, $12^{\circ} 30^{\prime}$ 49"S), 


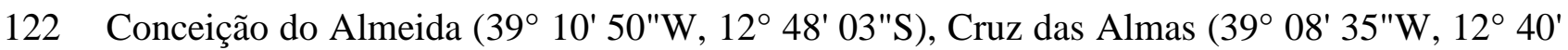

123 59"S), Dom Macedo Costa (39 $12^{\prime} 23^{\prime \prime} \mathrm{W}, 12^{\circ} 53^{\prime}$ 06"S), Governador Mangabeira (39 $02^{\prime}$

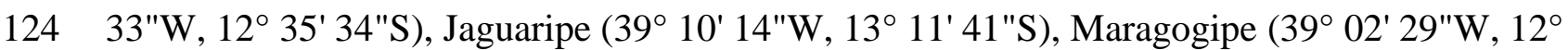

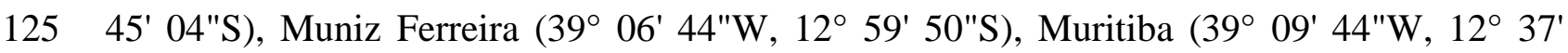

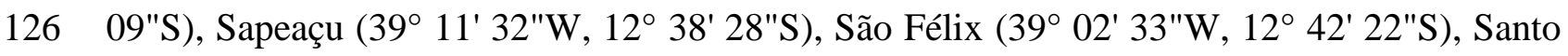
127 Amaro da Purificação (38 50' 54"W, $12^{\circ} 32^{\prime} 27 " \mathrm{~S}$ ), São Felipe (39॰ 02' 50"W, $12^{\circ} 44^{\prime}$ 00"S), 128 Santo Antônio de Jesus (39 $\left.18^{\circ} 51^{\prime \prime W}, 12^{\circ} 58^{\prime} 34^{\prime \prime S}\right)$, São Miguel das Matas (39 $27^{\prime} 58^{\prime \prime} \mathrm{W}$, $12912^{\circ} 58^{\prime} 45^{\prime \prime S}$ ) and Varzedo (39 $20^{\prime} 44^{\prime \prime} \mathrm{W}, 12^{\circ} 58^{\prime} 40^{\prime \prime S}$ ). One grove per municipality was 130 sampled; each was no larger than $3 \mathrm{Ha}$, and consisted of 'Pera' sweet orange grafted on 131 Rangpur lime. The choices of evaluation method, number of groves per municipality, citrus 132 variety and grove size were based on CGS sampling procedures previously recommended for 133 the Recôncavo Baiano region (Silva et al., 2009). In each grove a 'W'-shaped path was 134 followed in which 30 plants were arbitrarily chosen and thoroughly visually evaluated for the presence of typical CGS symptoms. CGS prevalence in the region was then calculated as the 136 proportion of groves with affected plants, whereas incidence was estimated as the proportion 137 of symptomatic plants in each grove.

A

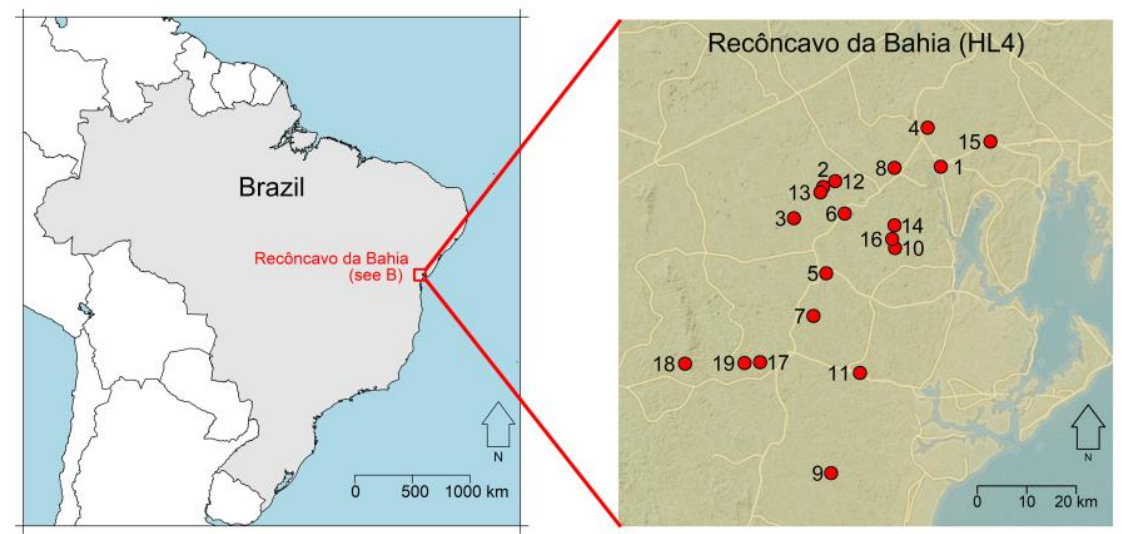

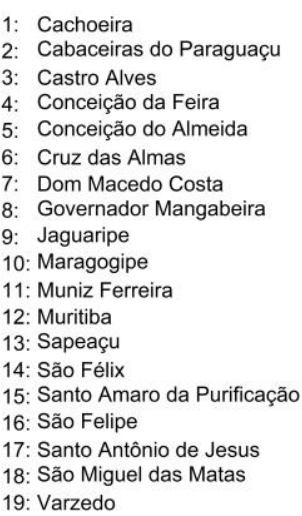

2: Cabaceiras do Paraguaçu

Castro Alves

Cruz das Almas

Governador Mangabeir

9: Jaguaripe

: Maragogipe

2: Muritiba

3: Sapeaçu

Santo Amaro da Purificação

7: Santo Antônio de Jesu

19: Varzedo

Figure 1. Locations in Recôncavo of Bahia (our Hierarchical Level 4) that were sampled for disease. Only the 19 (of the 20) municipalities in the region with at least 100 ha of citrus groves were sampled. (A) Location of the region in Brazil. (B) The 19 locations which were sampled. The maps were produced using the R packages maps (Becker et al., 2018) and OpenStreetMap (Fellows, 2019).

Data thus collected were the basis for examining the spatiotemporal patterns in HL1, HL2 and HL3. Ten groves of 'Pêra' sweet orange grafted on Rangpur lime (ranging from six to ten years old) were selected in three separate subregions of the Cruz das Almas municipality. Following a 'W'-shaped path, 30 plants were inspected in each grove. The number of inspected plants in each leg of the path was chosen according to the grove's shape and size. The position of each plant in each leg of the path was chosen before starting the procedure in each grove. The first five mature leaves from five different branches were examined in each plant's quadrant (two within planting rows and two between rows) in search of typical symptoms. The proportions of symptomatic leaves, quadrants and leaves were then 
calculated. The evaluations began in August 2006 and were perfomed monthly until February 2008.

\section{Temporal patterns}

Monthly mean incidence (proportion of symptomatic plants, quadrants or leaves) was calculated by averaging data from the ten sampled groves and used to plot disease progress curves.

\section{Weather data and distributed lag analysis}

The following variables were recorded daily by the Embrapa Cassava \& Tropical Fruits weather station, $10 \mathrm{~km}$ east of the three evaluated groves: average rain $(\mathrm{mm})$; days of rain each month; minimum, mean and maximum air temperature $\left({ }^{\circ} \mathrm{C}\right)$ and mean air relative humidity (\%). Data were organized in a monthly set and a distributed lag analysis was performed against $p s l$ (i.e. the proportion of symptomatic leaves) considering time lags of up 6 months. Distributed lag analysis is a regression used to predict current values of a dependent variable based on both the current value of an explanatory variable and the lagged (past period) values of that same variable (Laranjeira et al., 2003; Chatfield, 2004; Paul et al., 2007).

\section{Spatial pattern and dynamics}

To examine relations between the distinct levels of our spatial hierarchy, HL1 (among quadrants of a plant), HL2 (plants of a grove) and HL3 (groves in the region), the index of dispersion $(D)$ and the Binary Power Law were used (Madden \& Hughes, 1995). The sampling units $(N)$ were respectively the plant quadrants (HL1), the plants (HL2) and the groves (HL3); and the potential diseased entities (n) were leaves (HL1 and HL2) and plants (HL3). The hierarchical levels had the following combinations of $N, n: 1200,5$ (HL1); 300, 20 (HL2); 10, 30 (HL3).

The observed variance $\left(\mathrm{V}_{\mathrm{obs}}\right)$ as well as the expected binomial variance $\left(\mathrm{V}_{\text {bin }}\right)$ were calculated for each hierarchical level and evaluation date (Madden \& Hughes, 1995; Madden, Hughes \& Vandenbosch, 2007), in order to obtain the index of dispersion $\left(D=\mathrm{V}_{\mathrm{obs}} / \mathrm{V}_{\mathrm{bin}}\right)$. A $\chi^{2}$ test was used to assess whether there was any departure from randomness. The index of dispersion is used to assess the spatial pattern of a single hierarchical level on a given evaluation date. Values of $D$ higher than 1 were considered indicators of aggregation of symptomatic plants, those lower than 1 were taken to reflect a regular pattern. Those values which did not statistically differ from 1 were an indication of randomness, that is, a distribution of symptomatic plants without any regularity or aggregation.

The Binary Power Law, an adapted form of the Taylor Power Law for proportional data where variances do not increase monotonically with means (Madden et al., 2018), was used to assess the spatial heterogeneity of disease incidence. If the disease incidence was 
192 found to be aggregated (indicated by a slope, $b,<1$ ), this would favour the hypothesis that 193 auto-infection was an important driver of CGS incidence in groves. However, if the disease 194 incidence was uniform $(b>1)$, this would suggest that allo-infection contributed more to 195 CGS incidence.

Whilst the index of dispersion considers individual datasets, the Binary Power Law (BPL) can be used to assess multiple data sets (Madden et al., 2018). The BPL uses observed variance and expected binomial variance to estimate the spatial heterogeneity of CGS.

$$
\log \left(V_{\text {obs }}\right)=\log (A)+b \log \left(V_{b i n}\right)
$$

A suitable $F$ test was used to determine the significance of the relations between $\log \left(\mathrm{V}_{\text {bin }}\right)$ and $\log \left(\mathrm{V}_{\text {obs}}\right)$ (Statistica 5.0, Tulsa, USA); goodness-of-fit was assessed via $R^{2}$ and an analysis of residual patterns $v s$. the expected values of $\log \left(\mathrm{V}_{\text {bin }}\right)$ (Madden \& Hughes, 1995); Residual normality was also tested (Looney \& Gulledge, 1985). The parameters corresponding to the intercept $(\log (A))$ and the regression slope $(b)$ were considered significant if different from 0 and 1, respectively ( $\mathrm{t}$ test, $p<0.05$ ) (Madden \& Hughes, 1995). The binary power law is used to assess the spatial pattern of a collection of evaluation dates in a given hierarchical level. A value $b>1$ was taken as an indication of underdispersion, whereas $b<1$ indicated overdispersion and $b=1$ randomness.

\section{Vertical pattern}

The variability in the proportion of symptomatic leaves ( $p s l$ ) among plant heights was evaluated in three randomly selected groves in July 2007 (these three groves were not part of the set of groves used to assess spatial patterns). Leaves at three heights, $0.7 \mathrm{~m} ; 1.3 \mathrm{~m}$ and 2.0 $\mathrm{m}$ (treatments) were sampled in each of 30 plants (replications) per grove (block) in a total of 270 sampling units. For each of these units, 20 leaves were evaluated and the number of infected leaves was scored. These data were analysed using a generalized linear mixed model for binomial counts via the R package lme 4 (Bates et al., 2015), taking the grove as a (fixed) blocking factor, height as a (fixed) treatment effect and plant as a random effect. Significance was assessed by comparing nested models via Likelihood Ratio tests (Lewis, Butler \& Gilbert, 2011).

\section{Mathematical model}

We develop a simple compartmental model of the epidemiology of Z. citri, focusing on only the key features relevant to CGS epidemiology in Brazil (Fig. 2). Our core "singlegrower" model tracks the disease status of individual leaves on a representative plant within a single grove, since this is the scale at which disease symptoms are expressed and at which symptoms were scored in the survey. However, since the disease status of individual plants

228 sets the grove-scale dynamics, our model produces results of relevance to our Hierarchical 
229 Level 3 (i.e. an individual grove). The single-grower model is then extended to allow for area230 wide control (see Area-wide disease management, below), by accounting for disease spread 231 within two coupled populations of growers, those who control disease and those who do not.

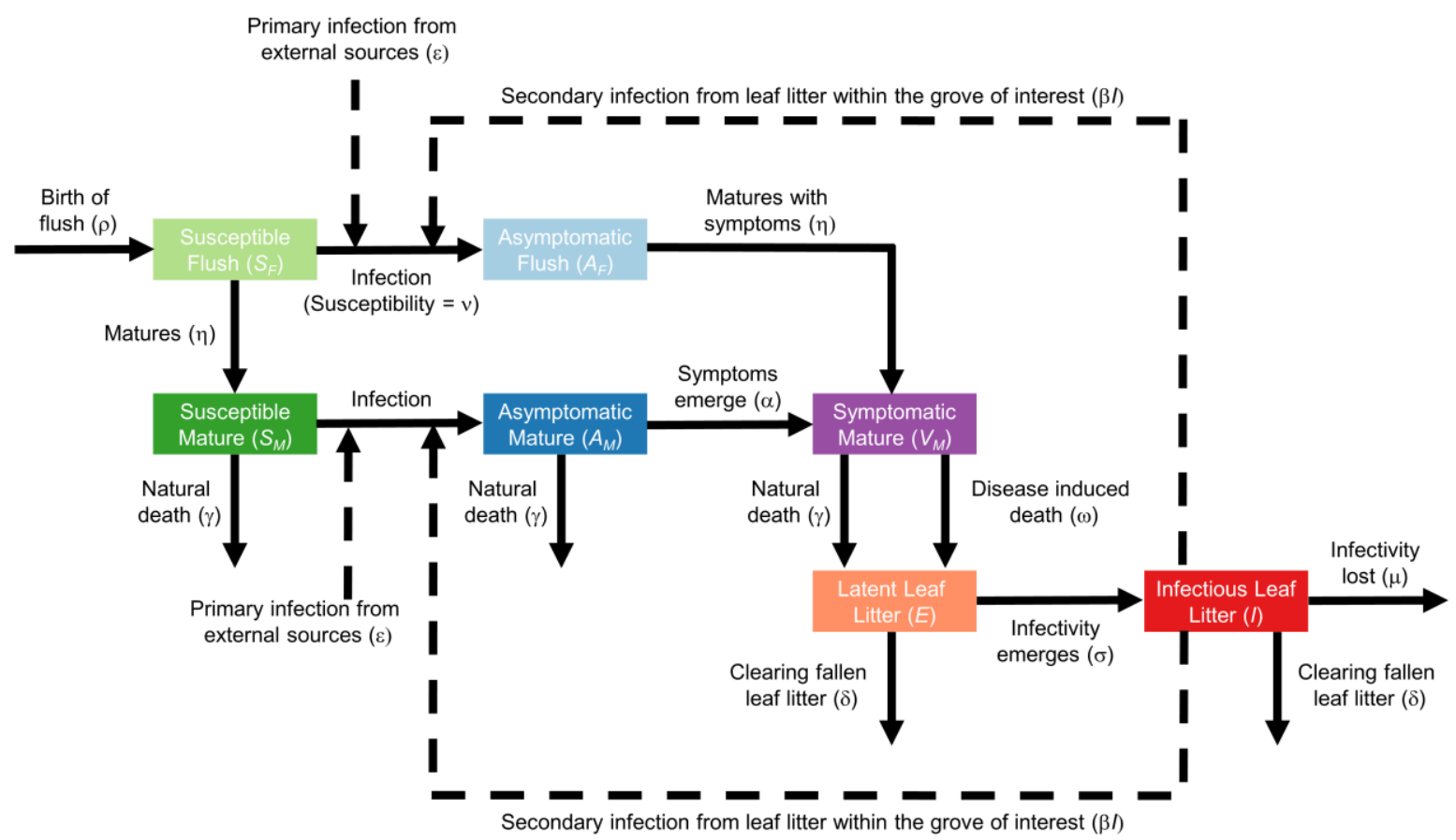

233 Figure 2. Schematic showing the structure of the single-grower mathematical model for within- and

We separate newly-created flush leaves from mature leaves in our model, since we scored only mature leaves for disease symptoms. We assume that flush transitions to maturity after an average of $1 / \eta$ units of time, where $\eta$ is the rate of maturation. We also assume that infected leaves do not show symptoms immediately, with the incubation period of mature 240 leaves assumed to average $1 / \alpha$ units of time, where $\alpha$ is the rate of development of symptoms. 241 We furthermore assume that only mature leaves can exhibit symptoms, with infected flush leaves starting to show symptoms immediately after reaching maturity (Fig. 2, Table 1).

A total of five leaf classes are therefore tracked: susceptible (i.e. healthy) flush $\left(S_{F}\right)$, asymptomatic infected flush $\left(A_{F}\right)$, susceptible mature leaves $\left(S_{M}\right)$, asymptomatic infected mature leaves $\left(A_{M}\right)$ and symptomatic mature leaves $\left(V_{M}\right)$. Since only mature leaves were scored for disease, the proportion of symptomatic leaves $(p s l)$ as recorded in the survey data corresponds to $\Gamma=V_{M} /\left(S_{M}+A_{M}+V_{M}\right)$. Mature leaves are assumed to abscise and fall to the ground at rate $\gamma$; symptomatic infected leaves are assumed to suffer additional diseaseinduced mortality at rate $\omega$ (Mondal \& Timmer, 2006a). This continual turnover of infected 
250 and uninfected leaves is offset by production of new flush; for simplicity we assume

251 production occurs at constant rate $\rho$ (Laranjeira et al., 2003)

252

\begin{tabular}{|c|c|c|c|}
\hline Symbol & Meaning & Value & Source \\
\hline$S_{F}$ & Number of susceptible (healthy) flush leaves & Varies & $\mathrm{n} / \mathrm{a}$ \\
\hline$A_{F}$ & Number of infected (asymptomatic) flush leaves & Varies & $\mathrm{n} / \mathrm{a}$ \\
\hline$S_{M}$ & Number of susceptible (healthy) mature leaves & Varies & $\mathrm{n} / \mathrm{a}$ \\
\hline$\overline{A_{M}}$ & $\begin{array}{l}\text { Number of infected (asymptomatic) mature } \\
\text { leaves }\end{array}$ & Varies & $\mathrm{n} / \mathrm{a}$ \\
\hline$V_{M}$ & Number of infected (symptomatic) flush leaves & Varies & $\mathrm{n} / \mathrm{a}$ \\
\hline$E$ & $\begin{array}{l}\text { Number of infected fallen leaves that are not yet } \\
\text { sporulating }\end{array}$ & Varies & $\mathrm{n} / \mathrm{a}$ \\
\hline$I$ & $\begin{array}{l}\text { Number of infected fallen leaves that have } \\
\text { started sporulating }\end{array}$ & Varies & $\mathrm{n} / \mathrm{a}$ \\
\hline$t$ & Time (in months) & Varies & $\mathrm{n} / \mathrm{a}$ \\
\hline$\rho$ & Birth rate of flush & 6000 month $^{-1}$ & Turrell (1961) \\
\hline$\beta$ & $\begin{array}{l}\text { Rate of secondary infection from infected fallen } \\
\text { leaves }\end{array}$ & Fitted to data & See Fig. 9 \\
\hline$\varepsilon$ & $\begin{array}{l}\text { Rate of primary infection from outside focal } \\
\text { grove }\end{array}$ & Fitted to data & See Fig. 9 \\
\hline$v$ & Proportionate susceptibility of flush vs. mature & 1 & $\begin{array}{l}\text { Mondal \& Timmer } \\
(2003 b)\end{array}$ \\
\hline$\eta$ & Rate of maturation of flush to become mature & $1 / 3$ month $^{-1}$ & $\begin{array}{l}\text { Spiegel-Roy \& } \\
\text { Goldschmidt (1996) }\end{array}$ \\
\hline$\gamma$ & Rate of death of mature leaves & $1 / 9$ month $^{-1}$ & $\begin{array}{l}\text { Wallace A, Zidan ZI, } \\
\text { Mueller RT (1954) } \\
\text { Spiegel-Roy \& } \\
\text { Goldschmidt, (1996) }\end{array}$ \\
\hline$\alpha$ & Rate of emergence of symptoms & $1 / 2$ month $^{-1}$ & $\begin{array}{l}\text { Mondal \& Timmer } \\
\text { (2006b) }\end{array}$ \\
\hline$\omega$ & Rate of disease-induced death & $2 / 9$ month $^{-1}$ & Timmer et al. (2000) \\
\hline$\sigma$ & $\begin{array}{l}\text { Rate of emergence of infectivity on infected } \\
\text { fallen leaves }\end{array}$ & $1 / 2$ month $^{-1}$ & $\begin{array}{l}\text { Mondal \& Timmer } \\
\text { (2006b) }\end{array}$ \\
\hline$\mu$ & Rate of loss of infectivity on fallen leaves & 1 month $^{-1}$ & $\begin{array}{l}\text { Mondal \& Timmer } \\
(2003 b)\end{array}$ \\
\hline$\delta$ & Rate at which leaf litter is cleared & $\begin{array}{l}0 \text { month }^{-1} \\
\text { (scanned over } \\
\text { in assessing } \\
\text { controls) }\end{array}$ & $\begin{array}{l}\text { Litter clearance is not } \\
\text { common practice in } \\
\text { Brazil }\end{array}$ \\
\hline
\end{tabular}


Secondary infection within the grove of interest occurs at rate $\beta$ via sporulation off of

258 fallen leaf litter that was once an infected mature leaf (Mondal \& Timmer, 2006b; Mondal et 259 al., 2003; Timmer et al., 2000); this follows a latent period on the ground which averages $2601 / \sigma$ units of time. Tracking this within-grove secondary infection pathway requires us to track 261 a further two classes of leaf litter: latently infected $(E)$ and sporulating infectious $(I)$. The only 262 source of latently infected leaves is mature symptomatic (i.e. leaves in class $V_{M}$ ) abscising 263 from the tree; i.e. any pre-symptomatic infected leaves that abscise are assumed to not lead to 264 infectious litter, and there is no spread of the pathogen within the litter (Fig. 2, Table 1).

We assume that sporulating litter remains infectious for an average of $1 / \mu$ units of time, and that litter is potentially cleared by the grower at rate $\delta$. We also allow for primary infection from sources of inoculum outside the grove of interest. In our single-grower model we assume this occurs at a constant rate $(\varepsilon)$. We allow the susceptibility of flush to differ from that of mature leaves: the proportionate susceptibility of flush is assumed to be $v$ (with an equal effect on susceptibility to infection via both the primary and the secondary infection pathways) (Fig. 2, Table 1).

The system of equations defining the single-grower model is therefore as follows.

$$
\begin{aligned}
\frac{d S_{F}}{d t} & =[\text { Production }]-[\text { Primary Infection }]-[\text { Secondary Infection }]-[\text { Maturation }], \\
& =\rho-\varepsilon v S_{F}-\beta v S_{F} I-\eta S_{F}, \\
\frac{d A_{F}}{d t} & =[\text { Primaryinfection }]+[\text { Secondary infection }]-[\text { Maturation with symptoms }], \\
& =\varepsilon v S_{F}+\beta v S_{F} I-\eta A_{F}, \\
\frac{d S_{M}}{d t} & =[\text { Maturation }]-[\text { Primary infection }]-[\text { Secondary infection }]-[\text { Natural death }], \\
& =\eta S_{F}-\varepsilon S_{M}-\beta S_{M} I-\gamma S_{M}, \\
\frac{d A_{M}}{d t} & =[\text { Primaryinfection }]+[\text { Secondaryinfection }]-[\text { Natural death }]-[\text { Emergence of symptoms }], \\
& =\varepsilon S_{M}+\beta S_{M} I-\gamma A_{M}-\alpha A_{M}, \\
\frac{d V_{M}}{d t} & =[\text { Emergence of symptoms }]-[\text { Natural death }]-[\text { Disease induced death }], \\
& =\left(\alpha A_{M}+\eta A_{F}\right)-\gamma V_{M}-\omega V_{M}, \\
\frac{d E}{d t} & =[\text { Litter fall from symptomatic infected }]-[\text { Emergenceof infectivity }]-[\text { Litter clearing }], \\
& =(\gamma+\omega) V_{M}-\sigma E-\delta E, \\
\frac{d I}{d t} & =[\text { Emergence of infectivity }]-[\text { Loss of infectivity }]-[\text { Litter clearing }], \\
& =\sigma E-\mu I-\delta I .
\end{aligned}
$$

274 A reference implementation of the model in the programming language $\mathrm{R}$ ( $\mathrm{R}$ Core Team, 275 2018) is available at https://github.com/nikcunniffe/Citrus-Greasy-Spot; it relies on the $\mathrm{R}$ 
package deSolve (Soetaert et al., 2010) for numerical solution of ordinary differential equations.

\section{Area-wide disease management}

A key simplification in our model is that the rate of primary infection is held constant. For disease management attempted by a single grower in isolation this is a reasonable assumption, inasmuch as the primary infection pathway is totally unaffected by control done within the grove. However, if other growers were also to attempt to control disease, this would clearly lead to a reduction in the amount of exported inoculum by these growers. In turn this would lead to a reduction in rates of primary infection across the entire region, since all growers would then suffer less infection. To account for this feedback between the local intensity of disease control and area-wide rates of primary infection, we extended the initial mathematical model to include two populations of grower: controllers (C) and non-controllers (NC). This modified model allows us to understand the performance of area-wide management.

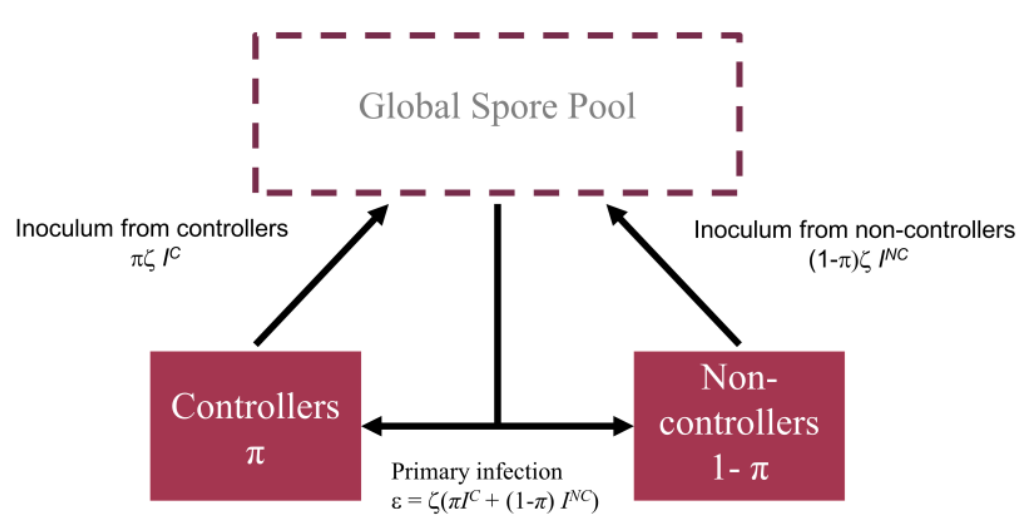

Figure 3. Schematic showing the structure of the mathematical model for area-wide implementation of control. The contribution of a grove to the area-wide primary infection rate depends on its control status. Inoculum from both types of growers mixes in the global spore pool and falls on any single grove of either type in equal measure.

We assume these two groups differ in how they manage CGS; the controllers undertake localised control and clear leaf litter at rate $\delta$. The non-controllers do not clear litter (i.e. have $\delta$ fixed at zero). We also assume that there is no spatial structure, thus all growers in the region of interest within each class are homogenous in their control practices and grove size. The model therefore tracks the average disease dynamics experienced by a typical grower in each class. For simplicity we furthermore assume that all inoculum causing primary infection is generated from somewhere within the modelled region, i.e. there is no very longdistance spread from outwith the set of groves tracked by our model or from more local sources of inoculum within the region such as non-cultivated citrus.

Under this scenario, the rate of primary infection $(\varepsilon)$ is no longer constant but should vary as $\varepsilon=\varsigma\left(\pi I^{C}+(1-\pi) I^{N C}\right)$ (Fig. 3), in which $\pi$ is the proportion of growers controlling disease and $I^{C}$ and $I^{N C}$ correspond to the levels of infection in typical groves of controllers and 
309 non-controllers, respectively. To ensure the results of the area-wide model are consistent with 310 the underlying single-grower model, we set the constant of proportionality, $\varsigma$, as $\varsigma=\varepsilon / I_{\infty}$, 311 where $I_{\infty}$ is the equilibrium level of infection in the absence of control and $\varepsilon$ is the rate of 312 primary infection, both lifted from the core single-grower model.

The new model for the controllers is defined as follows, with terms that differ from the 314 single-grower model - or which differ between controllers and non-controllers - highlighted 315 in red. Note the additional superscripts on the state variables, e.g. $S_{F}^{C}$ corresponds to $S_{F}$ for 316 growers which control disease (the corresponding state variable for the non-controllers is $\left.317 S_{F}^{N C}\right)$.

$$
\begin{aligned}
& \frac{d S_{F}^{C}}{d t}=\rho-\varsigma\left(\pi I^{C}+(1-\pi) I^{N C}\right) \vee S_{F}^{C}-\beta \vee S_{F}^{C} I^{C}-\eta S_{F}^{C}, \\
& \frac{d A_{F}^{C}}{d t}=\varsigma\left(\pi I^{C}+(1-\pi) I^{N C}\right) \vee S_{F}^{C}+\beta \vee S_{F}^{C} I^{C}-\eta A_{F}^{C}, \\
& \frac{d S_{M}^{C}}{d t}=\eta S_{F}^{C}-\varsigma\left(\pi I^{C}+(1-\pi) I^{N C}\right) S_{M}^{C}-\beta S_{M}^{C} I^{C}-\gamma S_{M}^{C}, \\
& \frac{d A_{M}^{C}}{d t}=\varsigma\left(\pi I^{C}+(1-\pi) I^{N C}\right) S_{M}^{C}+\beta S_{M}^{C} I^{C}-\gamma A_{M}^{C}-\alpha A_{M}^{C},
\end{aligned}
$$$$
\frac{d V_{M}^{C}}{d t}=\alpha A_{M}^{C}+\eta A_{F}^{C}-\gamma V_{M}^{C}-\omega V_{M}^{C},
$$$$
\frac{d E^{C}}{d t}=(\gamma+\omega) V_{M}^{C}-\sigma E^{C}-\delta E^{C} \text {, }
$$$$
\frac{d I^{C}}{d t}=\sigma E^{C}-\mu I^{C}-\delta I^{C} .
$$

319 The equations for growers who do not control disease are very similar:

$$
\begin{aligned}
& \frac{d S_{F}^{N C}}{d t}=\rho-\varsigma\left(\pi I^{C}+(1-\pi) I^{N C}\right) \nu S_{F}^{N C}-\beta \nu S_{F}^{N C} I^{N C}-\eta S_{F}^{N C}, \\
& \frac{d A_{F}^{N C}}{d t}=\varsigma\left(\pi I^{C}+(1-\pi) I^{N C}\right) \nu S_{F}^{N C}+\beta \nu S_{F}^{N C} I^{N C}-\eta A_{F}^{N C}, \\
& \frac{d S_{M}^{N C}}{d t}=\eta S_{F}^{N C}-\varsigma\left(\pi I^{C}+(1-\pi) I^{N C}\right) S_{M}^{N C}-\beta S_{M}^{N C} I^{N C}-\gamma S_{M}^{N C}, \\
& \frac{d A_{M}^{N C}}{d t}=\varsigma\left(\pi I^{C}+(1-\pi) I^{N C}\right) S_{M}^{N C}+\beta S_{M}^{N C} I^{N C}-\gamma A_{M}^{N C}-\alpha A_{M}^{N C}, \\
& \frac{d V_{M}^{N C}}{d t}=\alpha A_{M}^{N C}+\eta A_{F}^{N C}-\gamma V_{M}^{N C}-\omega V_{M}^{N C}, \\
& \frac{d E^{N C}}{d t}=(\gamma+\omega) V_{M}^{N C}-\sigma E^{N C}, \\
& \frac{d I^{N C}}{d t}=\sigma E^{N C}-\mu I^{N C} .
\end{aligned}
$$


The only qualitative difference between the models for the two types of grower is that the $\delta I$ and $\delta E$ terms are absent from the final equation for the non-controlling growers.

\section{Results}

\section{Spatial variability among plant heights}

The proportion of symptomatic leaves at individual heights $(0.7 \mathrm{~m}, 1.3 \mathrm{~m}, 2.0 \mathrm{~m})$ on individual plants varied between 0.70 (i.e. 14 out of 20) and 1.0 (i.e. 20 out of 20), with overall mean 0.90 . There was a significant interation between grove and height (Likelihood Ratio Test: $\chi_{4}^{2}=22.56 ; p<0.001$, with an increase in disease severity with height in the most heavily infected grove, but no increase in the other two groves. Since there was only a response to height in one out of the three groves tested, we conclude that there was no reliable effect of height on disease severity (see also Supplementary Text 1).

\section{Prevalence and Incidence in Recôncavo da Bahia}

Typical symptoms of CGS were found in all sampled groves, leading to a $100 \%$ prevalence. Symptoms were also detected on every assessed plant in each single grove,

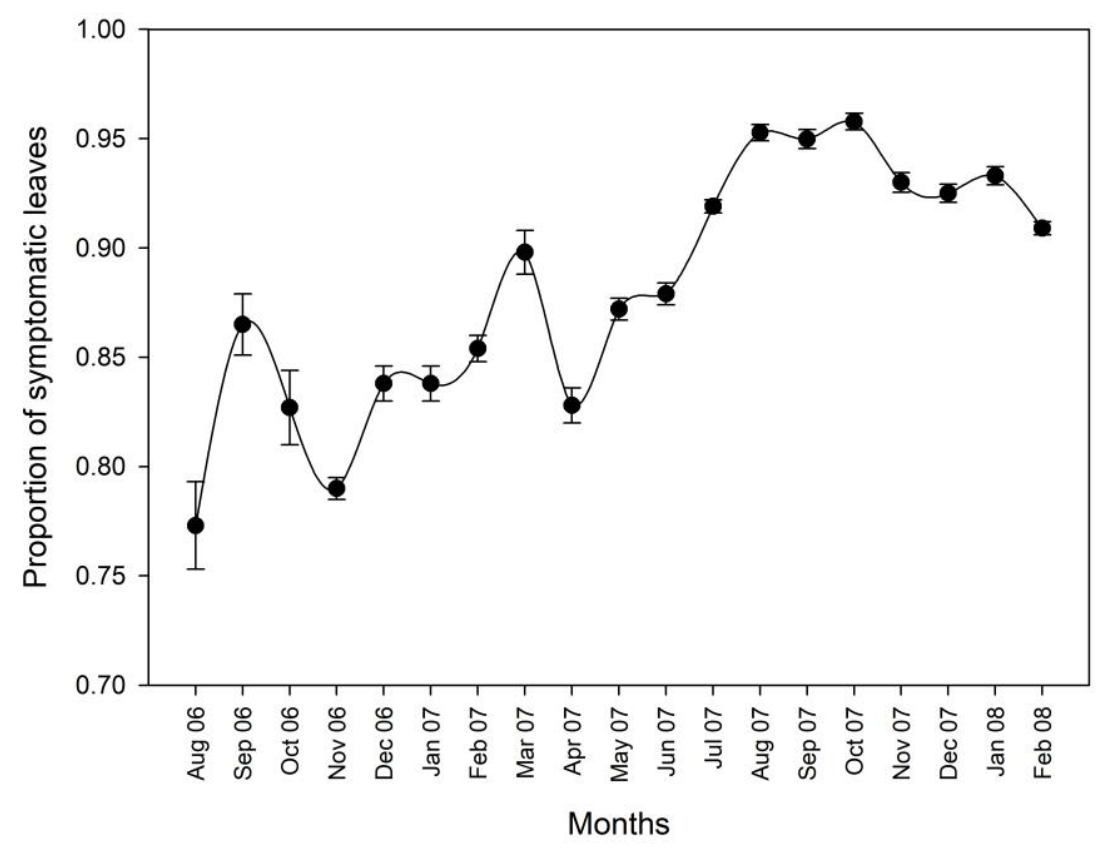

\section{Months}

340 Figure 4. Progress of citrus greasy spot measured as proportion of symptomatic leaves in ten sweet orange 341 groves between August 2006 and February 2008 in Cruz das Almas, Recôncavo Baiano, Brazil. Bars 342 represent standard error. 
CGS temporal pattern

346

347

348

349

350

351

352

353

CGS symptoms were observed in $100 \%$ of evaluations, groves, plants and plant quadrants in each of the ten monthly sampled areas in the Cruz das Almas municipality. The only variability in these results was detected for the proportion of symptomatic leaves ( $p s l)$, which increased over 19 months, ranging from 0.77 in August 2006 to a maximum of 0.96 in October 2007 (Fig. 4). Although there was some systematic linear increase in the incidence, oscillations were found. However, there were insufficient data to test for periodic behaviour in $p s l$, e.g. via spectral analysis.

\section{Weather variables}

Distributed lag analysis performed between the weather variables and CGS psl did not reveal any significant relationship (Fig. 5).

\section{Spatial pattern and dynamics}

It was not possible to perform any analysis of data from HL3 (among groves) and HL4 (among municipalities) due to lack of variability. In HL1 (plant quadrants) 58\% of $D$ values were statistically similar to 1 (randomness), whereas $2 \%$ were above 1 (aggregation), and $40 \%$ below 1 (regularity) (Fig. 6A). At HL2 (plants), the index of dispersion $(D)$ had $76 \%$, $12 \%$ and $12 \%$ of observations statistically equal to, higher than and lower than 1 , respectively (Fig. 6B). No relationship between $D$ and the observed range of CGS psl could be observed, for plant quadrants or plants (Fig. 6). The predominance of $D$ values $\leq 1$ for HL1 and HL2 could be confirmed by temporal dynamics of $D$ means (Fig. 7) and the very low standard errors reinforce this point.

The binary power law was also used to analyse the CGS spatial patterns in HL1 and HL2. The regression between $\log \left(\mathrm{V}_{\text {bin }}\right)$ and $\log \left(\mathrm{V}_{\text {obs }}\right)$ was highly significant for both spatial levels (Fig. 8). The residuals were randomly distributed, but in both cases the coefficients of determination were below 0.7 . The regression parameters, $\log (A)$ and $b$, were significantly lower than 0 and 1 , respectively [(log(A): $t(380)=-16.2, p<.00001)$ ), (b: $t$ $(380)=28.7, p<.0001)]$ for HL1 (quadrants) and HL2 (plants) $[(\log (\mathrm{A}): t(190)=-4.4, p<$ $.00001)),($ b: $t(190)=13.1, p<.00001)]$ (Fig. 8). 


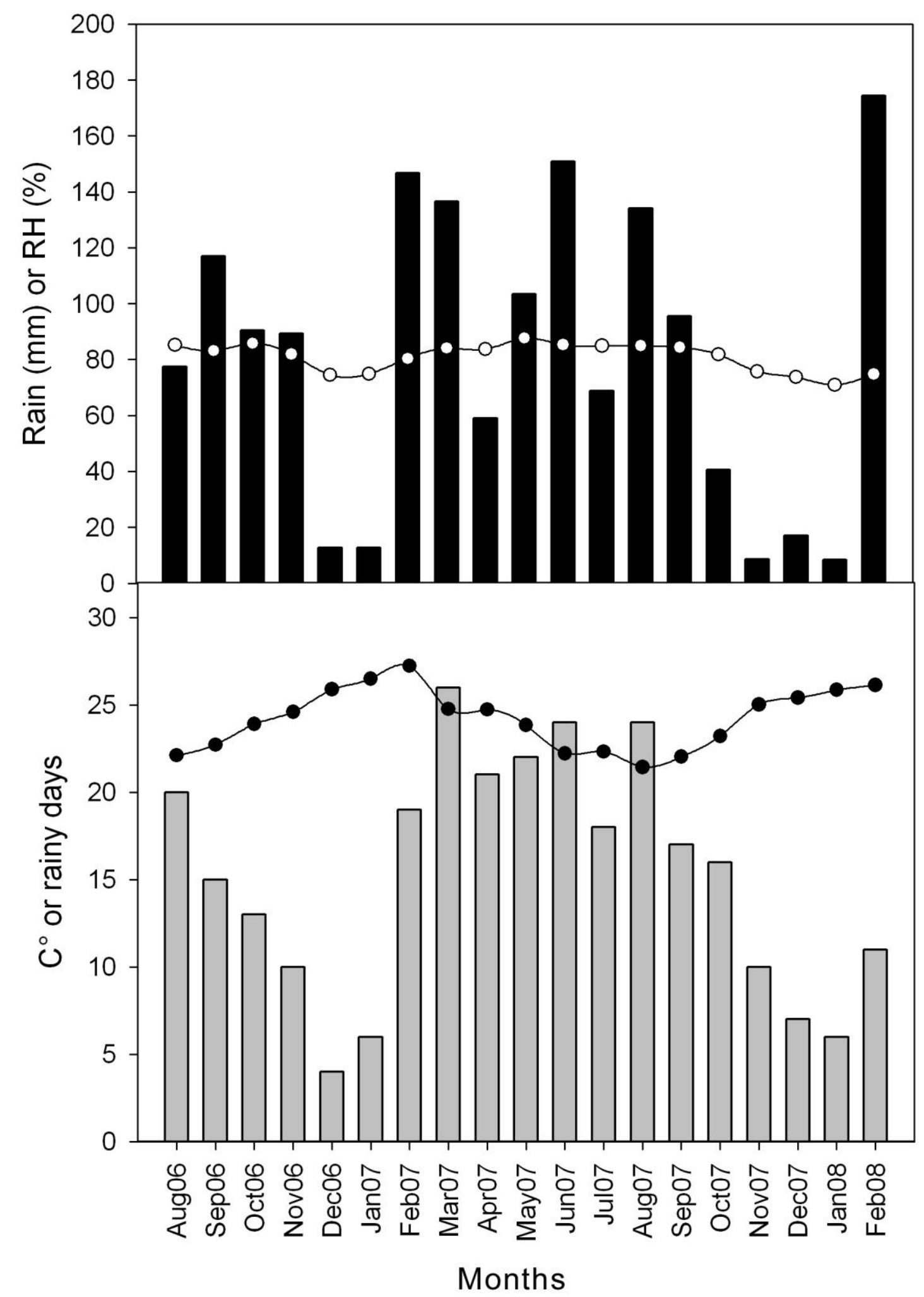

Figure 5. Mean monthly values for weather variables in Recôncavo Baiano between August 2006 and 


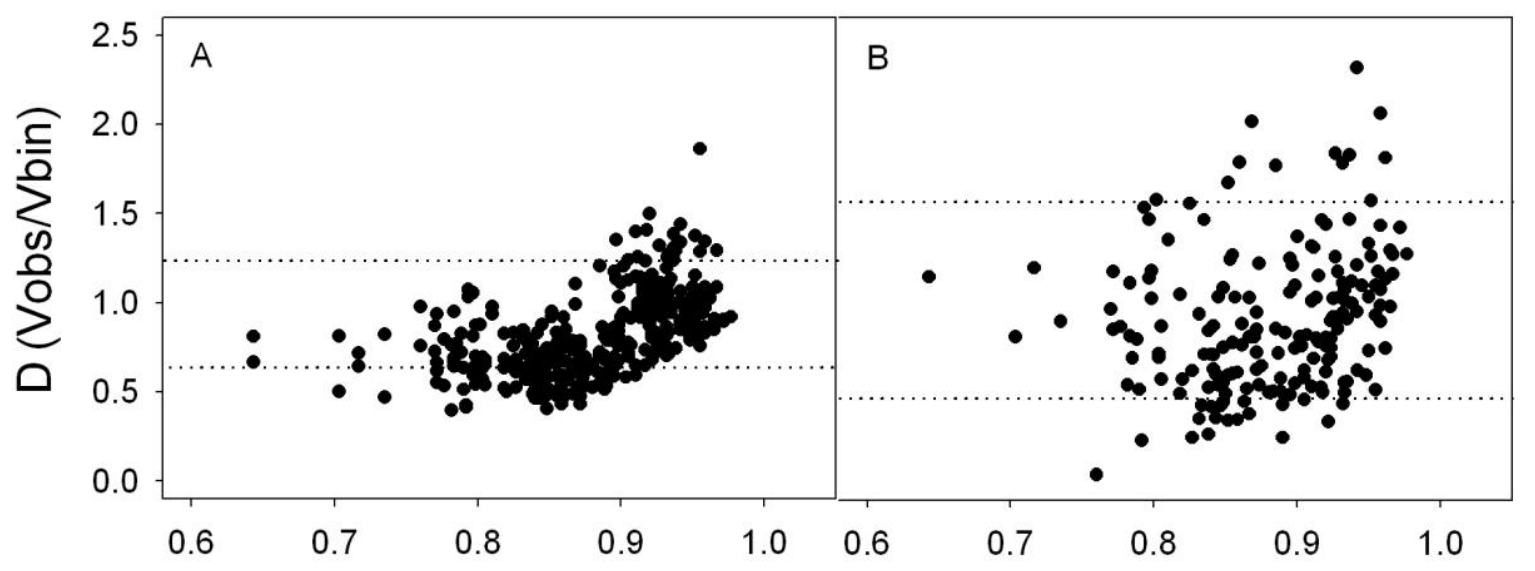

Figure 6. Relationship between citrus greasy spot incidence in leaves and binomial index of dispersion (D) dotted lines indicate the randomness upper and lower limits for each spatial level. Ds indicate aggregation

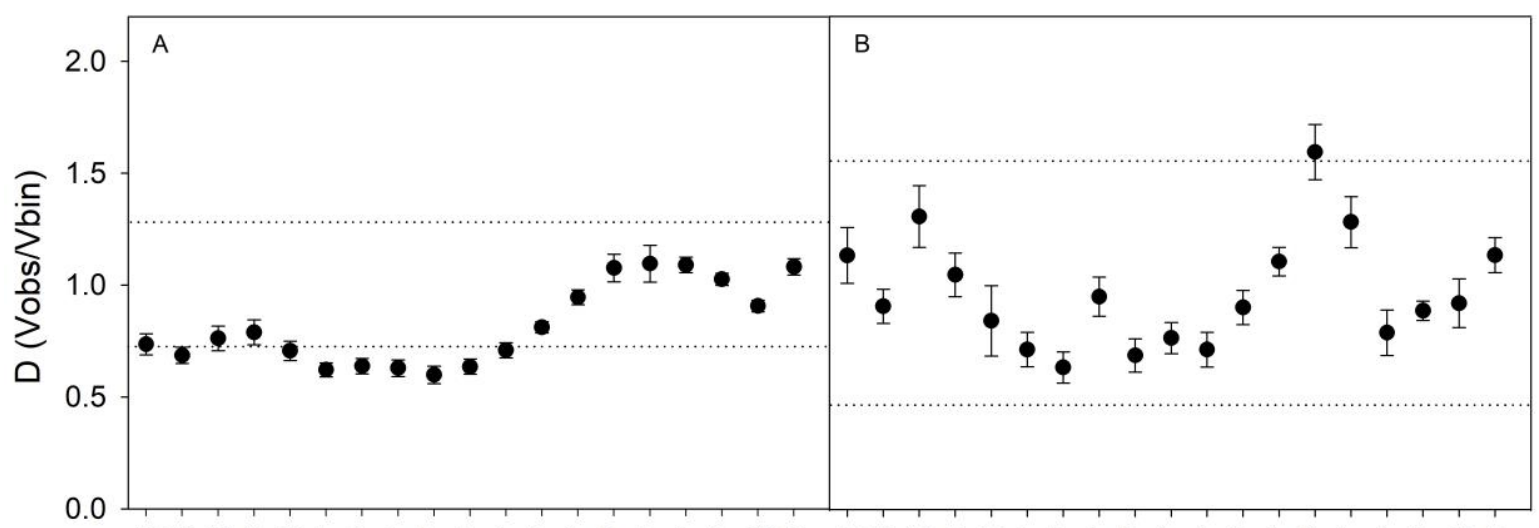

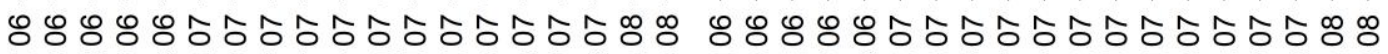

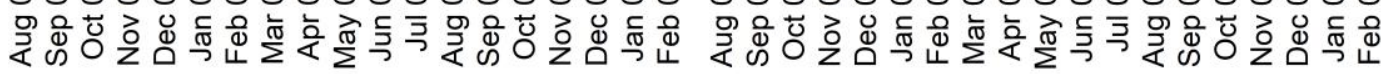

391 in ten sweet orange groves in Recôncavo Baiano, Brazil. Values not different from 1 indicate randomness; 


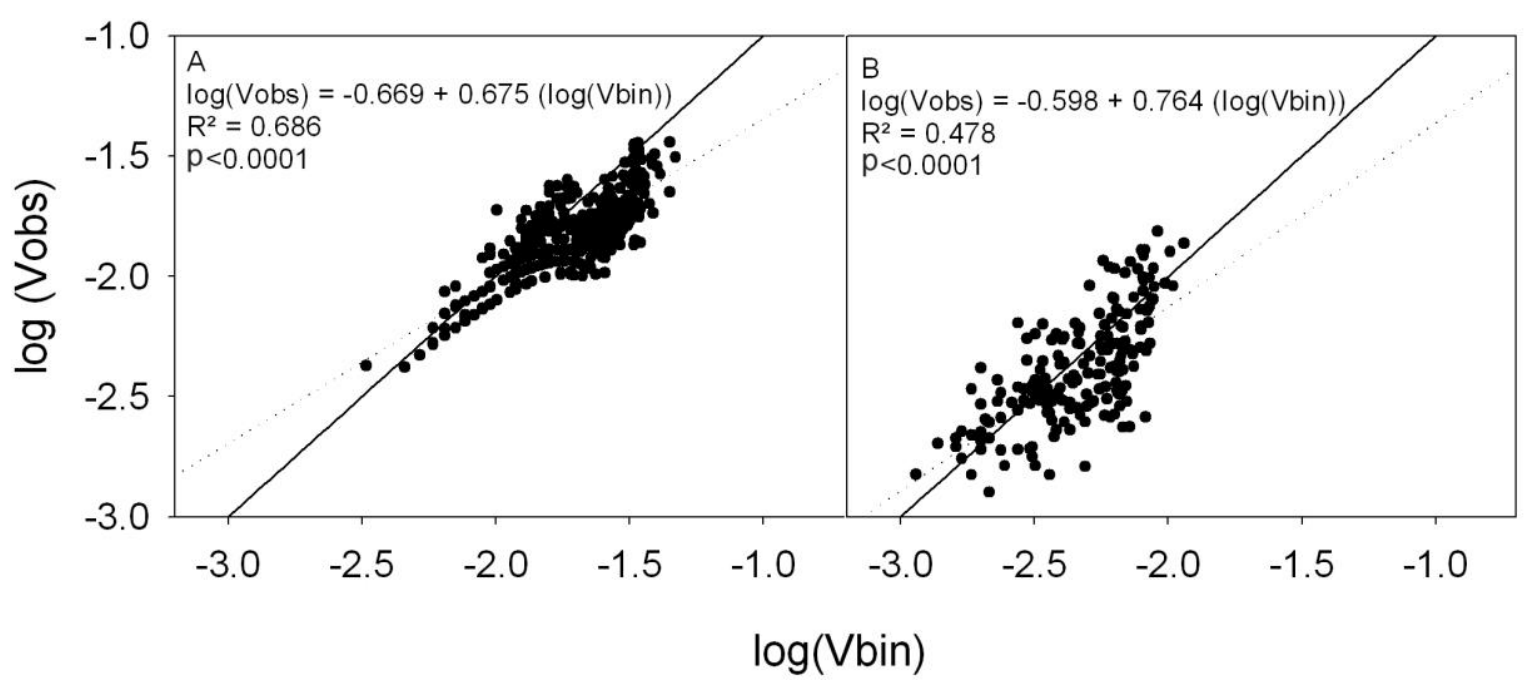

Figure 8. Binary power law. Relationship between the logarithms of observed variance and binomial variance for citrus greasy spot in quadrants $(A)$ and plants $(B)$ in ten sweet orange groves in Recôncavo Baiano, Brazil. Continuous line represents the expected relationship under randomness and the dotted line, the actual regressions. The regressions were significant $(p<0.0001)$ and the parameters $\log (A)$ and $b$

\section{Model parameterisation}

We assume that leaves mature after approximately three months (Spiegel-Roy \& Goldschmidt, 1996), and so set the rate at which flush transitions to become mature leaves to be $\eta=1 / 3$ month $^{-1}$. We furthermore assume that the average lifetime of a leaf is approximately one year (Wallace et al. 1954, Spiegel-Roy \& Goldschmidt, 1996), which after accounting for an average of three months spent as flush - means that the rate of natural death of mature leaves should be $\gamma=1 / 9$ month $^{-1}$. Figure 1 of Turrell (1961) indicates that a ten-year old citrus tree would have approximately 70,000 leaves. Taking this as a rough estimate of the number of leaves on a mature tree in the absence of disease - predicted to be $\bar{S}_{F}=\rho / \eta$ and $\bar{S}_{M}=\rho / \gamma$ as the steady state of the system of differential equations for the single-grower model when there is no disease - allows us to fix the rate of production of flush to be $\rho=6,000$ month $^{-1}$ (where, in the light of the approximate nature of our calculation, we have rounded this estimate to only a single significant figure).

The incubation period between infection of a mature leaf and first emergence of symptoms is approximately two months (Mondal \& Timmer, 2006a), and so we take the rate of emergence of symptoms on mature leaves to be $\alpha=1 / 2 \mathrm{month}^{-1}$. Since the average lifetime of a diseased leaf is approximately three months (Timmer \& Gottwald, 2000; Timmer et al., 2000), 1/( $\gamma+$ $\omega)$ should be 3 months, which given our earlier estimate for the value of $\gamma$ allows us to set the rate of disease-induced death to be $\omega=2 / 9$ month $^{-1}$. Data presented in Mondal \& Timmer (2002) suggest it takes approximately two months for sporulation to start after an infected leaf falls to the ground, and that - under constant conditions - sporulation would cease after three 
months. We therefore take the rate at which pre-infectious leaf litter enters the infected class to be $\sigma=1 / 2$ month $^{-1}$, and the rate of loss of infectivity of infectious leaf litter to be $\mu=1$ month $^{-1}$ (since litter is actively producing spores for an average of one month).

We assume that recently emerged and mature leaves are equally susceptible (Mondal \& Timmer, 2006a), and so take the proportionate susceptibility to be $v=1$. Noting that clearing fallen litter is uncommon in Bahia, we take the default rate of clearance to be $\delta=0$ (although we scan over values of this parameter when we model disease management; see 428 below).

A

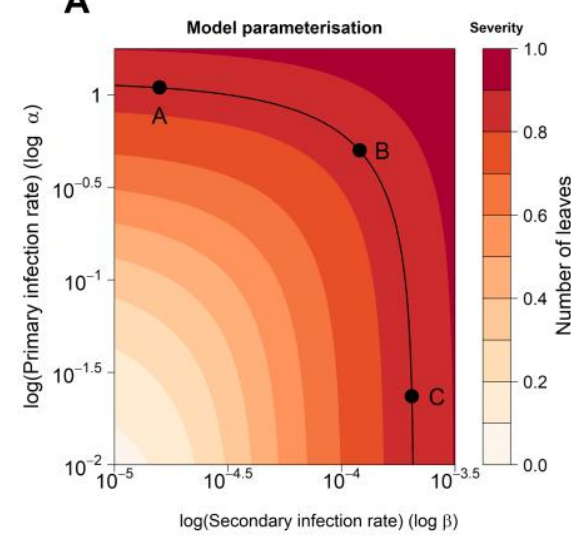

B

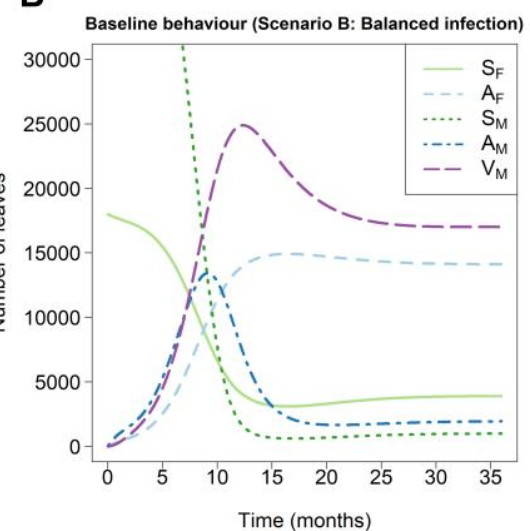

C

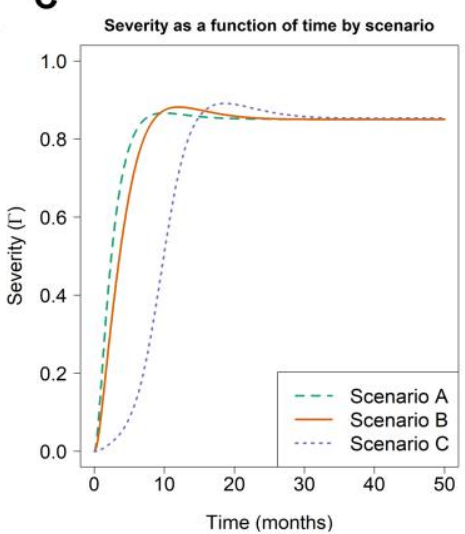

Figure 9. Parameterisation of the single-grower model. (A) Terminal disease severity as a function of the primary $(\varepsilon)$ and secondary $(\beta)$ infection rates (each axis is on a $\log 10$ scale). Pairs of values leading to severity 0.85 - which roughly matches our disease spread data (cf. Fig. 4) - are linked with the black curve. Three parameter scenarios are identified and marked with black dots: Scenario A (high primary infection but low secondary infection), Scenario B (balanced primary and secondary infection) and Scenario C (low primary infection but high secondary infection). (B) Baseline behaviour of the model in Scenario B, showing the numbers of leaves in each compartment on the average tree within a grove for three years after first introduction of the disease into a grove of mature trees. (C) Severity as a function of time under each parameterisation scenario.

The only remaining model parameters that remain to be fixed are the rates of primary $(\varepsilon)$ and secondary $(\beta)$ infection. We identify reasonable values of these parameters by searching for pairs of values leading to $p s l$ of $\Gamma=0.85$ when the model has reached its disease-present equilibrium, to match the data taken in our survey ( $c f$. Fig. 4). Given we are estimating a pair of parameters ( $\varepsilon$ and $\beta$ ) from a single datum (equilibrium $p s l$ ), there are an infinite number of pairs of parameter values which lead to the desired equilibirium severity

448 (marked by the black curve on Fig. 9A). Our current data do not allow us to distinguish the 449 values of these parameters in more detail. 
From this set of possible parameters, we identify three representative pairs of values corresponding to the following three illustrative scenarios.

452 Scenario A ("Primary-dominated"). High Primary, Low Secondary, with $\varepsilon \approx 1.1$ month $^{-1}$ 453 and $\beta \approx 1.6 \times 10^{-5}$ month $^{-1}$, in which most infection is caused by sources external to the grove 454 of interest.

455 Scenario B ("Balanced infection"). Balanced Primary and Secondary, with $\varepsilon \approx 5.0 \times 10^{-1}$ month $^{-1}$ and $\beta \approx 1.2 \times 10^{-4}$ month $^{-1}$, in which the epidemic is driven roughly equally from sources within the grove vs. external to the grove.

Scenario C ("Secondary-dominated"). Low Primary, High Secondary, with $\varepsilon \approx 2.3 \times 10^{-2}$ month $^{-1}$ and $\beta \approx 2.1 \times 10^{-4}$ month $^{-1}$, with most infection coming from within the grove of interest.

Disease reaches equilibrium following first introduction in a mature grove rapidly under all three scenarios (shown in Fig. 9B for the balanced infection scenario). At equilibrium the rate of production of new susceptible flush is equal to the sum of the outflows of flush due to leaf maturation and flush leaf infection, with the rate of flush maturation equal to sum of the rates of mature leaf infection and mature leaf natural death ( $c f$. Fig 2; the sum of flows into and out of each compartment are equal, for each compartment). While there are differences in the initial response of severity to time between scenarios (Fig. 10C), reflecting a transition from "monomolecular-like" (primary-dominated scenario) to "logistic-like" (secondary-dominated scenario) disease progress curves (Madden et al. 2007), differences are relatively slight. Any distinction between the scenarios is certainly not captured in the data we have taken here, since the disease was already very well-established in the groves we studied. This reiterates the idea that further experimental work would be required to conclusively disentangle the relative rates of the two infection pathways.

\section{Modelling disease control}

Although not captured in our data, the relative balance of primary and secondary infection can have strong implications upon which types of control can be successful (Bassanezi et al., 2013; Bergamin Filho et al., 2016). To explore this further, we consider removal of fallen leaf litter. Following the logic concerning roguing given in Cunniffe et al. (2014), if the leaf litter is removed every $\Delta$ months, then the average fallen leaf remains on the ground for $\Delta / 2$ months, and so - assuming that all leaves are removed on each round of litter removal - the appropriate rate of removal in our model is $\delta=2 / \Delta$.

\section{Sensitivity analysis of the single-grower model}

We performed a sensitivity analysis to examine how changes in parameter values affected terminal disease severity in the single-grower model across each of the primaryinfection dominated, the balanced and the secondary-infection dominated scenarios. The response of the equilibrium severity did not vary between scenarios for the majority of the 
epidemiological parameters we considered (Figs. 10D-I), since the effects of these parameters do not interact with the rates of infection. Most patterns were intuitive. For example, the severity decreases as the relative susceptibility of flush (v) decreases (Fig. 10D). We note, however, that it is unsurprising that terminal severity did not vary with the average latent period for leaf litter (1/ $\sigma$; Fig. 10I), since the default parameterisation for the rate of removal of litter $\delta$ is 0 . As it is never cleared, the litter will always become infectious and thus contribute to terminal severity, irrespective of the latent period on the ground.

A

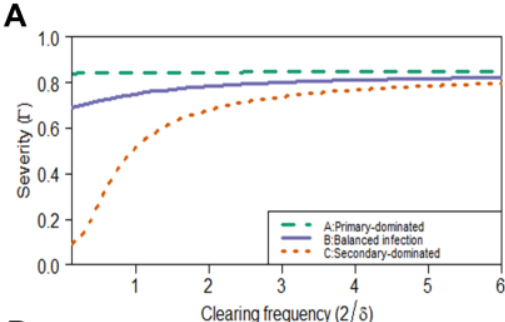

D

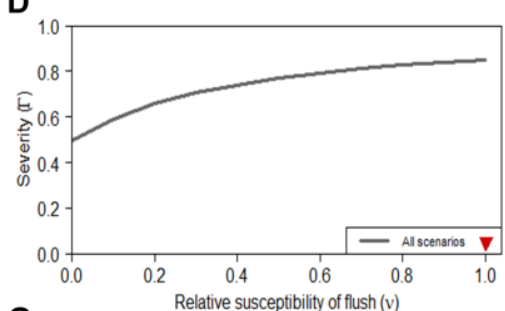

G

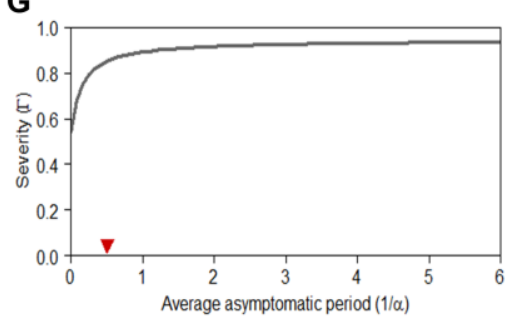

B

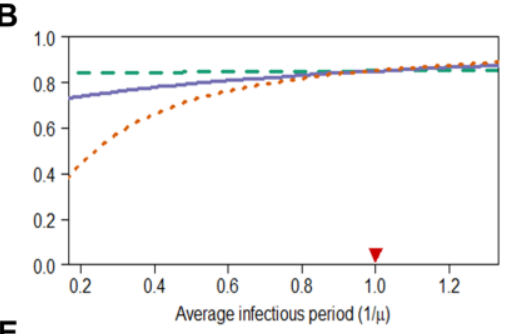

E

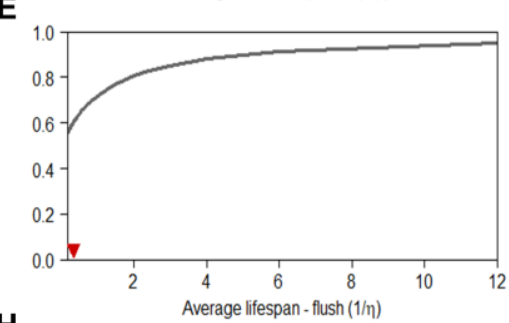

H

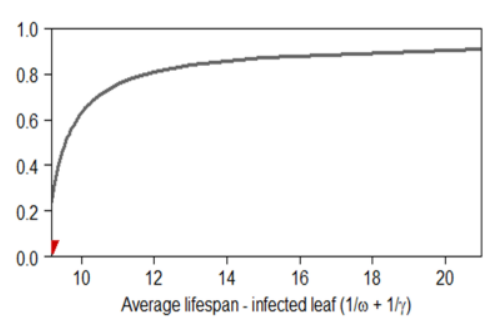

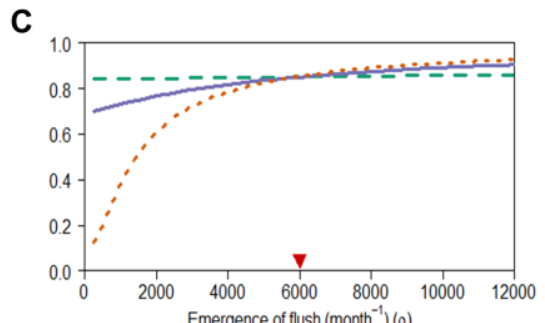

$\mathbf{F}$

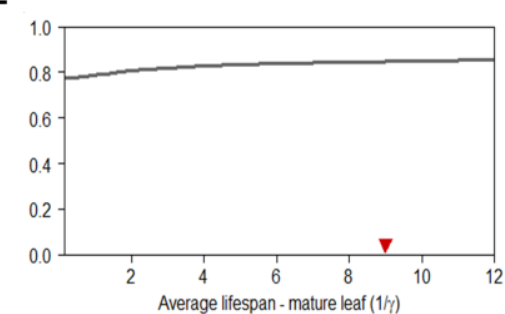

I

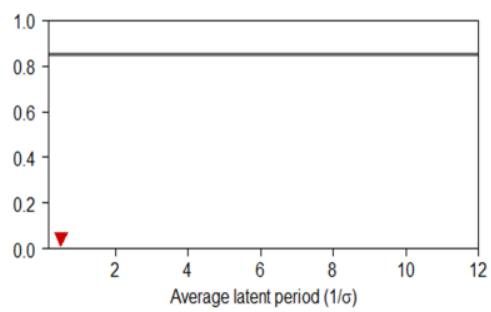

Figure 10. Sensitivity Analysis: impact of parameter values on equilibrium severity. (A) Interval between successive clearances of leaf litter. (B) Average lifespan of diseased leaf (without control). (C) Birth rate of flush. (D) Relative susceptibility of flush to mature leaves. (E) Average age of maturity ("lifespan") of flush. (F) Average lifespan of mature leaves in a disease-free system. (G) Average asymptomatic period. (H) Average infectious period of fallen leaves. (I) Average latent period. Red arrows on the $x$-axes show default parameterisation. All periods are in months. The parameter scenario only affects the responses panels A-C, in which cases the scenarios are distinguished by different types and colours of line; in panels D- I the responses in all three parameter scenarios are co-incident.

Responses to three parameters, however, did vary across infection rate scenarios. An increased birth rate of flush ( $\rho$; Fig. 10C) has its greatest impact on the secondary-dominated scenario. Similarly, short infectious periods $(1 / \mu$; Fig. 10B) caused substantial reductions in terminal severity in the secondary-dominated scenario, though infectious periods $>2$ months resulted in little change from the baseline parameterisation (1 month). The changes in terminal severity for the primary-dominated and balanced infection scenarios were less severe. In the single-grower version of the model, there is no dependence of rates of primary infection on the amount of infection present within the grove, so changes in infectious periods have little impact on the amount of infection coming from these sources. 

removal (Fig. 10A) reveals significant differences in the predicted effectiveness of control

518 based on the relative balance of primary and secondary infection. In particular, under 519 Scenario A, the high rate of inoculum ingress from outside the grove means that purely 520 localised control based on local removal of litter has very little effect on the disease severity, no matter how frequently the litter is removed. Even very high rates of local litter removal under Scenario B - in which both primary and secondary infection have a role in driving the epidemic dynamics - also do not greatly affect the level of disease (e.g. weekly leaf removal leads to a reduction in terminal severity from $85 \%$ to around $70 \%$ ). However unsurprisingly in Scenario $\mathrm{C}$ - in which local inoculum almost entirely drives the epidemic - local removal of leaf litter can be very effective, even if only practised by the single grower in question.

Scenario A (Primary-dominated)

Scenario B (Balanced Infection)

Scenario C (Secondary-dominated) scenario (Scenario C).
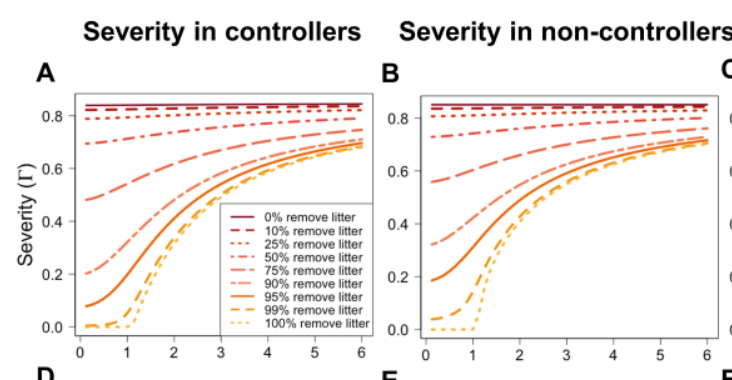

Average severity
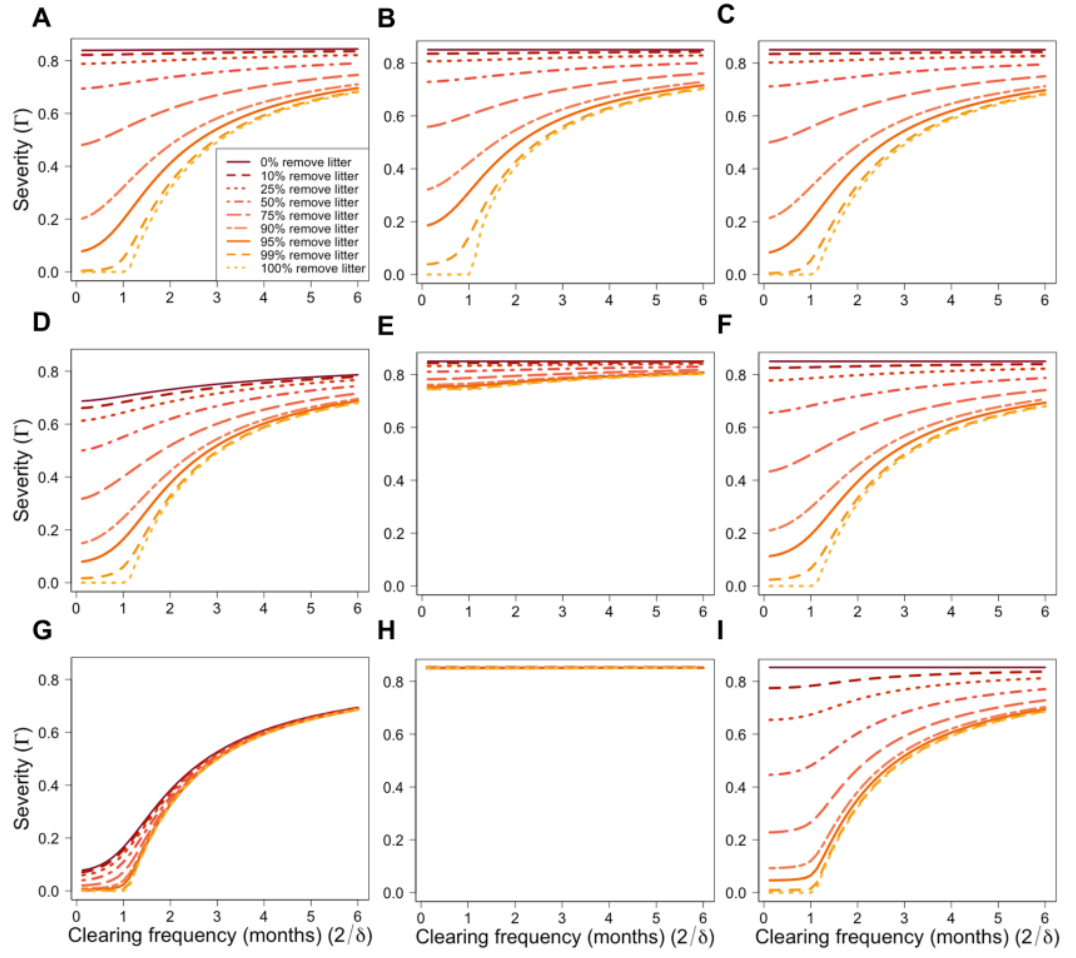

Figure 11. Area-wide disease management. The impact of a proportion $\square$ of growers controlling disease by local removal of leaf litter (at average frequency $2 / \delta)$ on disease severity in groves of controllers $\left(\Gamma_{C}\right.$; panels $\mathbf{A}, \mathbf{D}$ and $\mathbf{G})$, non-controllers $\left(\Gamma_{N C}\right.$; panels $\mathbf{B}, \mathbf{E}$ and $\left.\mathbf{H}\right)$ and on average over all groves $\left(\pi \Gamma_{C}+(1-\pi) \Gamma_{N C}\right.$; panels $\mathbf{C}, \mathbf{F}$ and $\left.\mathbf{I}\right)$. The top row (panels A-C) shows the primary-dominated parameter scenario (Scenario A); the middle row (panels D-F) shows the balanced infection parameter scenario (Scenario B), and the bottom row (panels G-I) shows the secondary-dominated parameter 


\section{Area-wide disease management}

While the results given in Fig. 10A provide a useful baseline, disease control by removal of leaf litter is more likely to be more successful if adopted by an entire community of growers, since this would reduce sources of inoculum for all groves. We demonstrate this using our model of area-wide control (Fig. 11), assuming that the rate of primary infection, $\varepsilon$, depends on the proportion of growers $(\pi)$ practicing control (see Methods). The performance of disease management within the set of groves doing control depends strongly on the parameter scenario (Figs. 11A,D,G), with the results shown in Fig. 10A providing an upper bound on the severity when no one else clears leaf litter (i.e. when $\pi=0$ ). Similarly, the results shown in Fig. 10A provide a lower bound on severity for growers not doing control (Figs. 11B, E, H). In all parameter scenarios, removal of litter every month or so is required for eradication of disease if there is $100 \%$ compliance. However, the performance averaged over all growers when there is an intermediate level of compliance (Figs. 11C, F, I) depends on the parameter scenario. For example, monthly removal of litter by $75 \%$ of growers leads to average severities over all groves of $0.56,0.50$ and 0.27 in our primary-dominated, balanced infection and secondary-dominated parameter scenarios, respectively.

\section{Frequency of litter removal for eradication}

Area-wide eradication requires all growers to participate (i.e. $\pi=1$ ). Our numerical work suggests it also requires growers to remove leaf litter at least once a month or so, and that this minimum removal frequency does not depend on the parameter scenario. This can be explained using the basic reproduction number $\left(R_{0}\right)$. In particular, in the area-wide disease spread model, when $\pi=1$ and so when all growers control disease, the basic reproduction number is given by

$$
\begin{aligned}
R_{0} & =\frac{1}{\mu+\delta}\left((\beta+\varsigma) v \bar{S}_{F}+(\beta+\varsigma) \bar{S}_{M} \frac{\alpha}{\alpha+\gamma}\right) \frac{\sigma}{\sigma+\delta}, \\
& =\left(\frac{(\beta+\varsigma) \rho}{\mu+\delta}\right)\left(\frac{\sigma}{\sigma+\delta}\right)\left(\frac{v}{\eta}+\frac{\alpha}{\gamma(\alpha+\gamma)}\right) .
\end{aligned}
$$

The expression can be understood by considering the number of infections caused by a single infected leaf introduced into the disease-free system, within which the numbers of susceptible flush and mature leaves are $\bar{S}_{F}=\rho / \eta$ and $\bar{S}_{M}=\rho / \gamma$, respectively. The initially infected leaf remains infectious for $\frac{1}{\mu+\delta}$ units of time. It infects flush leaves at net rate $(\beta+\varsigma) v \bar{S}_{F}$ and mature leaves at net rate $(\beta+\varsigma) \bar{S}_{M}$. Any (asymptomatic) infected flush leaf definitely becomes a symptomatic mature leaf, whereas an asymptomatic infected mature leaf becomes symptomatic before being abcised with probability $\frac{\alpha}{\alpha+\gamma}$ (since it has to develop symptoms and so move to the $V_{M}$ compartment before falling to the ground). In both cases mature leaves detach to become uninfectious fallen leaf litter, and become infectious before decaying with 
571 probability $\frac{\sigma}{\sigma+\delta}$. This completes a single infection cycle: combining the various rates and

572 probabilities leads to the expression for $R_{0}$ given above.

573

574

575

576

577

578

579

580

581

582

583

584

585

586

587

588

589

590

591

592

593

594

595

596

597

598

599

600

601

602

603

604

605

606

607

The expression for $R_{0}$ is a decreasing function of the litter clearance rate $\delta$, which - for all parameterisations of the model (Table 1) - is below 1 if $\delta>1.81$ per month. Given the relationship $\delta=2 / \Delta$, this correponds to litter removal every $\Delta=2 / 1.81 \sim 1.1$ months, i.e. the threshold obtained in all three parameter scenarios for the area-wide model (Figs. 11C,F,I). The particular parameter scenario is not important in setting this threshold because the value of $(\beta+\varsigma)$ is fixed at precisely the same value, i.e. that which leads to a terminal severity of 0.85 in the single-grove model in the absence of disease management (the numeric value is $(\beta+\varsigma) \approx 2.1 \times 10^{-4}$ month $\left.^{-1}\right)$.

\section{Discussion}

CGS symptoms were found in every single grove and plant, irrespective of sub-region, altitude, grove age or variety. This pattern was consistent over time for each of the ten sampled groves in Cruz das Almas, and so, at this spatial level (i.e. the region), CGS can be considered to be highly regularly dispersed. Our data therefore confirm the conclusion of the preliminary report of Silva et al. (2009) that CGS in Reconcavo is currently endemic in the sense that it is regularly found and very common in that particular area.

The level of $Z$. citri infection is more related to conditions for epiphytic growth than to the number of ascospores (Mondal \& Timmer, 2003b). We did not find evidence that CGS intensity in Recôncavo Baiano is higher on the lower canopy as was previously found in Florida (Mondal et al., 2003), perhaps since psl was so high for all heights. This can perhaps be linked to the negative logarithmic pattern for the number of trapped Z. citri ascospores at different heights reported in Florida; even at $7.5 \mathrm{~m}$ some spores were captured (Mondal et al., 2003). Nevertheless, considering that the closest CGS inoculum source is ground level litter (Mondal \& Timmer, 2006b), lack of variability over heights throughout regions indicates that conditions are conducive for $Z$. citri dispersion/infection and that CGS is very widespread.

The ubiquity of CGS was confirmed for almost all sampling units during the monthly evaluations in Cruz das Almas groves. The increase in $p s l$ was somewhat expected, as most reports show such pattern for Cuba, Costa Rica and Florida (Garcia et al., 1980; Hidalgo et al., 1997; Mondal \& Timmer, 2003a). However, as those studies were primarily concerned with the development of CGS symptoms on new shoots, they reported a strong seasonality, and had incidences ranging from as low as $30 \%$ to as high as $100 \%$. Here, as we focused on the presence of CGS on mature rather than on new leaves, we could evaluate what we consider the real incidence for the Recôncavo region, reflecting the epidemiology of the pathogen rather than the demography of its host. 
Our distributed lag analysis supported no link between disease severity and abiotic environmental drivers. In Florida it was shown that the less intense epiphytic growth occurred in dry months, with growth speed increasing during the summer (Mondal \& Timmer, 2003a). In Cuba, an increase in CGS incidence and severity during Summer was reported (rains and high relative air humidity) (Garcia et al., 1980). However, in Recôncavo da Bahia climatic conditions appear to provide no obstacle to CGS, with no extreme temperatures, as well as long periods of high relative air humidity and only short periods without rain. Such conditions are ideal for the $Z$. citri-citrus interaction.

Since no variability was found in the fourth and third levels of the spatial hierarchy (i.e. among municipalities or groves), they were not analysed. When such analyses were feasible (i.e. among plant quadrants and plants), the index of dispersion indicated a random pattern for single evaluations and at both spatial levels. However, the general spatial pattern was regularity $(\log (A)<0$ and $b<1)$ as shown by the binary power law. This favours the hypothesis that allo-infections (i.e. from inoculum coming from outside the grove) might be as important as auto-infections. This strengthens the case for area-wide management.

Spore trapping experiments could help to assess the allo-infection hypothesis. Another way of confirming the relative balance of auto- and allo-infection might be to collect data at lower disease severity levels, which could be used to determine the rates of primary and secondary infection $\varepsilon$ and $\beta$ in our single-grower mathematical model (cf. Fig. 9A). Targetted experimentation, e.g. performing litter removal in some experimental plots while allowing disease to progress unhindered in others, would be another way to begin to disentangle the balance of the routes of infection. However, very large plots might be required to obtain a detectable effect. Such data would also allow us to verify the time-dynamics of our model, and in particular to verify that the time-progression in the number of leaves in each compartment over time is plausible ( $c f$. Fig 10). However, we do not have such data in hand.

Given this uncertainty concerning the balance of the infection pathways, we restricted ourselves to a relatively simple mathematical model of the system, replicating only the important features of the $Z$. citri infection cycle, with all parameters taking constant values. Nevertheless, by systematising available knowledge on CGS epidemiology, our model allows us to understand potential effects of manangement. In particular, we have shown that cultural control - of the type that could be done by resource-poor growers in Northeastern Brazil might potentially be successful. However, assuming primary infection is indeed at least somewhat implicated in CGS epidemiology, area-wide management would almost certainly be required (Bassanezi et al., 2013; Bergamin Filho et al., 2016) (Fig. 11). Conclusions would be similar for any localised control affecting only secondary within-grove infection, e.g. accelerating the decay of inoculum by treating litter with urea (Mondal \& Timmer, 2003a).

In our single-grower model we assumed a constant rate of primary infection. This assumption is often made in models (e.g. Cunniffe et al., 2015), including in studies fitting models to data (see e.g. Parry et al., 2014). We later extended the model to include the behavior of other growers and the effects of area-wide control on any individual's local 
epidemic. We then assumed that the rate of primary infection depends on the average level of infection area-wide. Even without full participation, our model showed concerted efforts across growers lead to large reductions in disease severity for growers who manage disease.

Rates of primary infection will also be affected by regional environmental conditions, as well as the spatial structure of the landscape. Here we ignored spatial structure and assumed homogeneity amongst growers of the same type. However, relaxing this condition would be an interesting extension to the model. The relative balance of primary infection to secondary infection would also vary depending on the size of the grove of interest (Hilker et al., 2017), and its location within the landscape. Finally, in the area-wide model we assumed all primary infection was caused by inoculum produced within the set of citrus groves tracked. This allowed disease to be eradicated when all growers control disease. In practice some inoculum might come via very long-distance dispersal from outside the area of interest, or be produced on other sources such as non-cultivated citrus within the region. Our results are therefore an upper bound upon the levels of disease control that could be achieved. If other sources of inoculum do in fact exist, divergence from this optimal performance would be most significant for the scenario in which primary infection dominated (i.e. Scenario A).

Z. citri is already highly dispersed in Recôncavo of Bahia, with maximum CGS prevalence and incidence in plants and their quadrants, irrespective of the location of the groves or plant's age. This fact, associated with the high incidence in leaves seems a natural consequence of the way in which CGS has been viewed in that region; because it has never been considered important, it was never controlled. Hence, the incidence increased, but as this process has been cyclic and apparently quite slow, the disease is still not seen as a threat (Rodrigues, 2018). The situation resembles that previously in Florida, where prior to 1940 CGS was not considered a serious problem (Mondal \& Timmer, 2006a). Only when growers finally noted the disease was causing defoliation, did they begin to attempt control.

In light of our results, CGS can be regarded as endemic in Recôncavo da Bahia. Moreover, in Bahia state the disease is also found in other regions (unpublished). In contrast with the situation in São Paulo, the most important citrus producing region in Brazil, many diseases are not present in Recôncavo. For instance, this area is currently free from HLB (Candidatus Liberibacter spp.), leprosis (CiLV), citrus canker (Xanthomonas citri subsp. citri) and sweet orange scab (Elsinöe australis) (Laranjeira et al., 2005). In this context, at least for the region we are concerned with, CGS cannot be regarded as a minor citrus disease. Nevertheless, growers face a temporal continuity of both host (perennial crop with multiple flushings per year) and pathogen (putative abundant inoculum due to favourable weather and multiple inoculum sources) coupled to a host spatial continuity represented by more than 10,000 ha of citrus in the region (IBGE, 2017). Hence, due to its endemic status CGS control in Recôncavo will be a challenging task. Some growers try to invest in technology, but overall low input level farming represents the citrus industry. Citrus groves are established without long term planning and simple small-holder farming takes place. Growers often have a low educational level and low concern about general horticultural practices, soil management or plant protection. However, there is no evidence of different CGS intensity or perception according to groves' technological level (Rodrigues, 2018). 
690 CGS control in the Recôncavo region will probably demand a set of practices at a

691 frequency and cost which is incompatible with the current technological level and economic 692 position of local citrus growers. Moreover, due to the abundance of inoculum, favourable 693 weather and long-distance wind-dispersion of ascospores, localised control attempts in small 694 groves may have a low probability of success. Therefore, if growers decide to tackle this 695 disease, it is advisable that their efforts should be coordinated on a regional basis. Additional 696 data would allow us to confirm this preliminary conclusion, as well as to continue to model 697 the system. Collecting more disease spread data and using these data to parameterize more 698 detailed mathematical models will form the basis of our future work on this pathosystem.

\section{Acknowledgements}

701

The authors would like to thank Mr Decio de Oliveira Almeida for technical 703 support, and Dr Matthew Castle, Dr Adam Hall and Mr Elliott Bussell for useful discussions. 704 FFL and ACFS are fellows of Conselho Nacional de Desenvolvimento Científico e 705 Tecnológico $(\mathrm{CNPq})$. The authors thank the anonymous reviewers and the editors for 706 comments which were instrumental in greatly strengthening the final paper. Conceived and 707 designed experiments: SXBS, FFL. Provided funds and materials: SXBS, FFL, HPSF. 708 Performed the experiments: SXBS. Analyzed the data: SXBS, FFL. Designed the model: 709 FFL, NJC. Analysed the model: NJC, REMW, FFL. Wrote the paper: FFL, NJC, REMW, 710 SXBS. Contributed to drafting the manuscript: FFL, NJC, REMW, SXBS, ACFS. Part of this 711 paper is from a MSc dissertation presented by SXBS to the Universidade Federal do 712 Recôncavo da Bahia.

713 


\section{References}

Bassanezi RB, Montesino LH, Gimenes-fernandes N et al., 2013. Efficacy of Area-Wide Inoculum Reduction and Vector Control on Temporal Progress of Huanglongbing in Young Sweet Orange Plantings. Plant Disease 97, 789-796.

Bates D, Machler M, Bolker B, Walker, S, 2015. Fitting Linear Mixed Effects Models using Ime 4. Journal of Statistical Software 67, 1-48.

Becker RA, Wilks AR. 2018. maps: Draw Geographical Maps. R package version 3.3.0. https://CRAN.R-project.org/package=maps

Bergamin Filho A, Inoue-Nagata AK, Bassanezi RB et al., 2016. The importance of primary inoculum and area-wide disease management to crop health and food security. Food Security 8, 221-238.

Chatfield, 2004. The Analysis of Time Series: An Introduction. New York: Chapman \& Hall.

Cunniffe NJ, Laranjeira FF, Neri FM, DeSimone RE, Gilligan C, 2014. Cost-effective control of plant disease when epidemiological knowledge is incomplete: modelling Bahia bark scaling of Citrus. PLOS Computational Biology 10, e1003753.

Cunniffe NJ, Stutt ROJH, DeSimone RE, Gottwald TR, Gilligan CA, 2015. Optimising and Communicating Options for the Control of Invasive Plant Disease When There Is Epidemiological Uncertainty. PLOS Computational Biology 11, 1-24.

Diaz J, Brown O, Herrera L,1985. Influence of greasy spot (Mycosphaerella citri) Whiteside on Valencia orange yields. Centro Agricola 12, 127-137.

Fellows I (2019) OpenStreetMap: Access to Open Street Map Raster Images. R package version 0.3.4. https://CRAN.R-project.org/package=OpenStreetMap

Fortin MJ, Dale MRT, 2005. Spatial analysis: a guide for ecologists.

Garcia R, Aguilar H, Herrera Y, 1980. Variaciones estacionales de la enfermedad mancha grasienta (Mycosphaerella citri) en la region de Jaguey Grande, Matanzas. Citricos y otros frutales. Centro Agrícola Suplemento, 107-119.

Hidalgo H, Sutton TB, Arauz F, 1997. Epidemiology and control of citrus greasy spot on Valencia orange in the humid tropics of Costa Rica. Plant Disease.

Hilker FM, Allen LJS, Bokil VA et al., 2017. Modeling virus coinfection to inform management of Maize Lethal Necrosis in Kenya. Phytopathology 107, 1095-1108.

IBGE, 2017. Quantidade produzida, valor da produção, área plantada e área colhida da lavoura permanente. Produção agrícola municipal (PAM).

Laranjeira F, Amorin L, Bergamin Filho A, Aguilar-Vildoso C, Coletta Filho H, 2005. Fungos, procariotos e doenças abióticas.

Laranjeira F, Filho A, Amorim L, Gottwald T, 2003. Dinâmica espacial da clorose variegada dos citros em três regiões do Estado de São Paulo. Fitopatologia Brasileira. 
Lewis F, Butler A, Gilbert L, 2011. A unified approach to model selection using the likelihood ratio test. Methods in Ecology and Evolution. 2, 155-162.

Looney SW, Gulledge TR, 1985. Commentaries: Use of the correlation coefficient with normal probability plots. American Statistician.

Madden L, Hughes G, 1995. Plant disease incidence: distributions, heterogeneity, and temporal analysis. Annual Review of Phytopathology 33, 529-564.

Madden L, Hughes G, Van den Bosch F, 2007. The Study of Plant Disease Epidemics (L Madden, G Hughes, F Van den Bosch, Eds,). St. Paul, Minnesota, USA: APS Press.

Madden LV, Hughes G, Bucker Moraes W, Xu M, Turechek, WW, 2018. Twenty-five years of the binary power law for characterizing heterogeneity of disease incidence. Phytopathology 108, 656-680.

Mondal SN, Gottwald TR, Timmer LW, 2003. Environmental factors affecting the release and dispersal of ascospores of Mycosphaerella citri. Phytopathology 93, 1031-1036.

Mondal S, Timmer L, 2003a. Effect of urea, $\mathrm{CaCO} 3$, and dolomite on pseudothecial development and ascospore production of Mycosphaerella citri. Plant Disease 87, 478483.

Mondal S, Timmer L, 2003b. Environmental factors affecting pseudothecial development and ascospore production of Mycosphaerella citri, the cause of Citrus greasy spot. Phytopathology 93, 1031-1036.

Mondal S, Timmer L, 2006a. Greasy spot, a serious endemic problem for citrus production in the Caribbean Basin. Plant Disease 90, 532-538.

Mondal SN, Timmer LW, 2006b. Relationship of the severity of citrus greasy spot, caused by Mycosphaerella citri, to ascospore dose, epiphytic growth, leaf age, and fungicide timing. Plant Disease 90, 220-224.

Parry M, Gibson GJ, Parnell S et al., 2014. Bayesian inference for an emerging arboreal epidemic in the presence of control. Proceedings of the National Academy of Sciences of the United States of America 111, 6258-62.

Paul PA, Lipps PE, De Wolf E et al., 2007. A distributed lag analysis of the relationship between Gibberella zeae inoculum density on wheat spikes and weather variables. Phytopathology 97, 1608-1624.

R Core Team, 2018. R: a language and environment for statistical computing. R Foundation for Statistical Computing, Vienna, Austria. https://www.R-project.org/

Rodrigues LSS, 2018. Diagnóstico fitossanitário participativo: ferramenta para o manejo de pragas da citricultura do Recôncavo Baiano. Dissertation. Universidade Federal do Recôncavo da Bahia, 92p.

Santos T, 2012. Parametrização e modelagem ex-ante da disseminação do HLB dos citros no Recôncavo da Bahia. Dissertation. Universidade Federal do Rêconcavo da Bahia, 103p. 
Sherman J, Burke JM, Gent DH, 2019. Cooperation and coordination in plant disease management. Phytopathology 109, 1720-1731.

Silva S, Laranjeira F, Soares A, Michereff S, 2009. Amostragem, caracterização de sintomas e escala diagramática da mancha graxa dos citros (Mycosphaerella citri) no Recôncavo Baiano. Ciência Rural 39, 896-899.

Silva S, Soares A, Almeida D, Santos-Filho H, Laranjeira F, 2015. Temporal patterns of citrus greasy spot-induced defoliation of sweet orange cultivars in Brazil. Annals of Applied Biology 167, 55-62.

Soetaert K, Petzoldt T, Woodrow Setzer R, 2010. Solving differential equations in R: package deSolve. Journal of Statistical Software 33, 1-25.

Spiegel-Roy P, Goldschmidt EE, 1996. Biology of citrus.

Timmer L, Gottwald T, 2000. Greasy spot and similar diseases. In: Timmer LW, Garnsey SM GJ, ed. Compendium of citrus disease. St. Paul, Minnesota, USA: The American Phytopathological Society, 25-29.

Timmer LW, Roberts PD, Darhower HM et al., 2000. Epidemiology and control of citrus greasy spot in different citrus-growing areas in Florida. Plant Disease 84, 1294-1298.

Turrell F, 1961. Growth of the photosynthetic area of citrus. Botanical Gazette 122, 284-298.

Wallace A, Zidan ZI, Mueller RT NC, 1954. Translocation of nitrogen in citrus trees. In: Proceedings of the American Society of Horticultural Science. American Society of Horticultural Science, 87-104.

Whiteside J, 1970. Etiology and epidemiology of citrus greasy spot. Phytopathology 60, 1409-1414.

Whiteside J, 1988. Greasy spot and greasy spot rind blotch. In: Timmer LW, Garnsey SM GJ, ed. Compendium of citrus diseases. St. Paul: American Phytopathological Society, 1517.

Xu XM, Butt DJ, Van Santen G, 1995. A dynamic model simulating infection of apple leaves by Venturia inaequalis. Plant Pathology 84, 1294-1298. 


\section{6}

817

818

819

820

821

822

823

824

825

826

827

828

829

830

831

832

833

\section{SUPPLEMENTARY TEXT 1}

We examined data on the number (out of 20) of symptomatic leaves at each of 3 heights on 30 plants in each of 3 groves.

The data were therefore as follows

\begin{tabular}{|c|c|c|c|c|c|}
\hline Height & Plant & Propsym & Grove & CountPlus & CountMinus \\
\hline $1 \mathrm{H} 1$ & P1 & 0.80 & G1 & 16 & 4 \\
\hline $2 \mathrm{HI}$ & P2 & 1.00 & G1 & 20 & 0 \\
\hline $3 \mathrm{H} 1$ & P3 & 1.00 & G1 & 20 & 0 \\
\hline $4 \mathrm{H} 1$ & P4 & 0.80 & G1 & 16 & 4 \\
\hline $5 \mathrm{H} 1$ & P5 & 0.90 & G1 & 18 & 2 \\
\hline
\end{tabular}

[265 rows omitted]

(there were 270 such measurements, for 3 heights on 30 plants in 3 groves [i.e. 90 plants in total]).

The raw data are plotted below. It suggests that there might be an increase in severity with height in Grove 1, but that any effect is more marked in Groves 2 and 3.

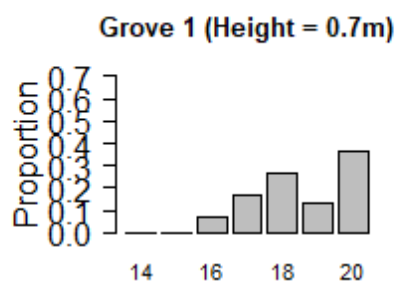

Number of symptomatic leaves

Grove 1 (Height $=1.3 \mathrm{~m})$

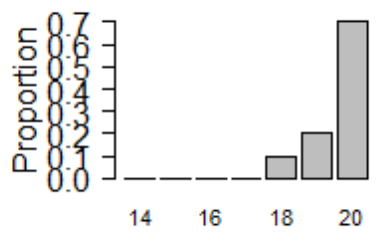

Number of symptomatic leaves

Grove 1 (Height $=2.0 \mathrm{~m}$ )

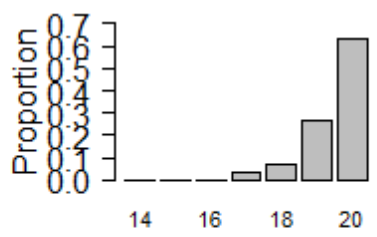

Number of symptomatic leaves
Grove 2 (Height $=0.7 \mathrm{~m}$ )

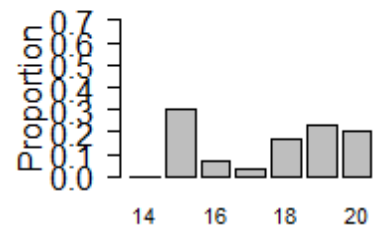

Number of symptomatic leaves

Grove $2($ Height $=1.3 \mathrm{~m})$

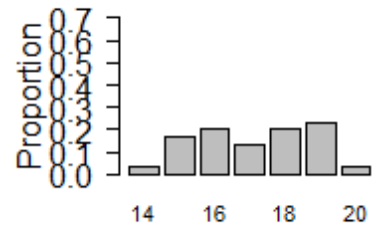

Number of symptomatic leaves

Grove 2 (Height $=2.0 \mathrm{~m})$

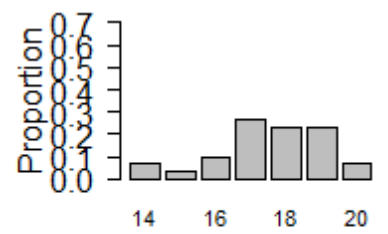

Number of symptomatic leaves
Grove 3 (Height $=0.7 \mathrm{~m})$

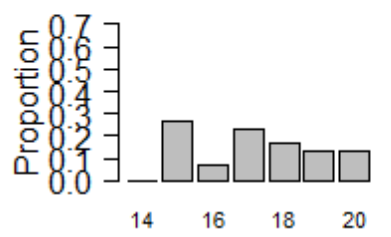

Number of symptomatic leaves

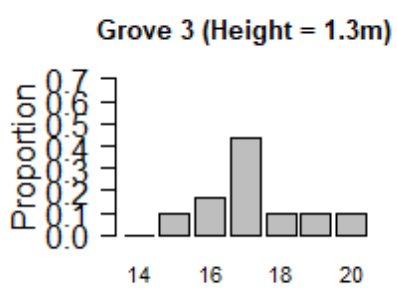

Number of symptomatic leaves

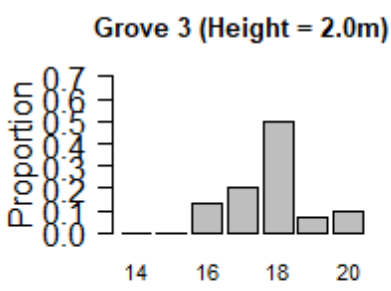

Number of symptomatic leaves

The mixed effect model we used to analyse these data uses a random effect for each plant to focus on the differences between disease severities on the same plant at different heights.

These are plotted overleaf; note that the histograms in rows two and three of the following figure plot out the differences on a plant-by-plant basis between the counts of infected leaves at $\mathrm{H} 2=1.3 \mathrm{~m}$ (row two) and $\mathrm{H} 3=2.0 \mathrm{~m}$ (row three) relative to $\mathrm{H} 1=0.7 \mathrm{~m}$. 
Grove 1 (Height $=0.7 \mathrm{~m})$

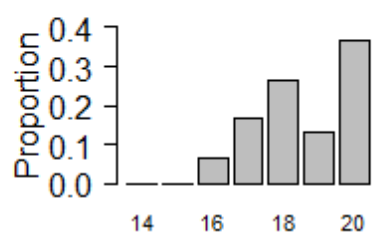

Number of symptomatic leaves

Grove $1: 1.3 \mathrm{~m}$ relative to $0.7 \mathrm{~m}$

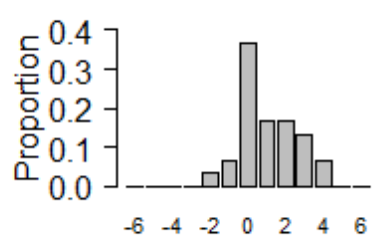

Change in symptomatic leaves

Grove 1: $2.0 \mathrm{~m}$ relative to $0.7 \mathrm{~m}$

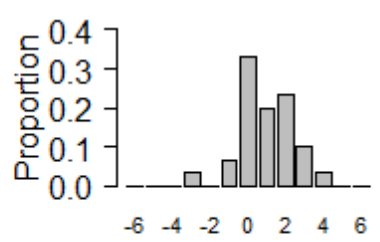

Change in symptomatic leaves
Grove 2 (Height $=0.7 \mathrm{~m})$

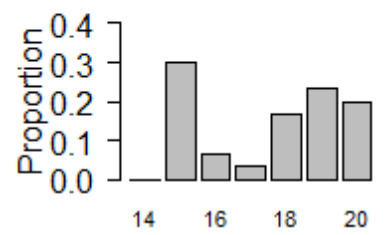

Number of symptomatic leaves

Grove 2: $1.3 \mathrm{~m}$ relative to $0.7 \mathrm{~m}$

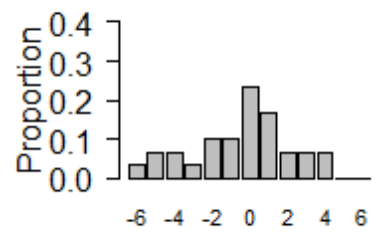

Change in symptomatic leaves

Grove 2: $2.0 \mathrm{~m}$ relative to $0.7 \mathrm{~m}$

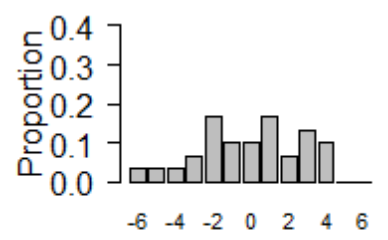

Change in symptomatic leaves
Grove 3 (Height $=0.7 \mathrm{~m}$ )

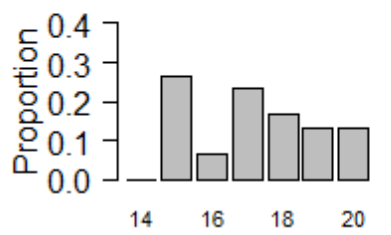

Number of symptomatic leaves

Grove $3: 1.3 \mathrm{~m}$ relative to $0.7 \mathrm{~m}$

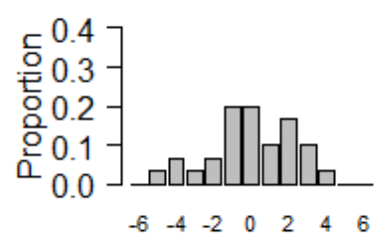

Change in symptomatic leaves

Grove 3: $2.0 \mathrm{~m}$ relative to $0.7 \mathrm{~m}$

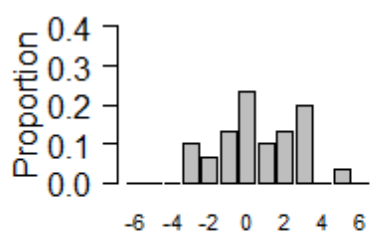

Change in symptomatic leaves

844 The effect of plant height on disease severity appeared equivocal between the three groves we tested; there appears to be an increase in Grove 1, but no clear pattern in Groves 2 and 3. This preliminary visual conclusion was supported by our statistical modelling. We fitted a mixed effect logistic regression and found statistically support for an interaction between the two fixed effects Height and Grove (in a model with a random intercept for each Plant).

glmer(cbind(CountPlus, CountMinus) Height + Grove + Height:Grove + (1 | Plant) family = binomial (link = "logit"), data = CGS_data)

853 The plot below shows the odds at different heights for different groves in this best-fitting 854 model.

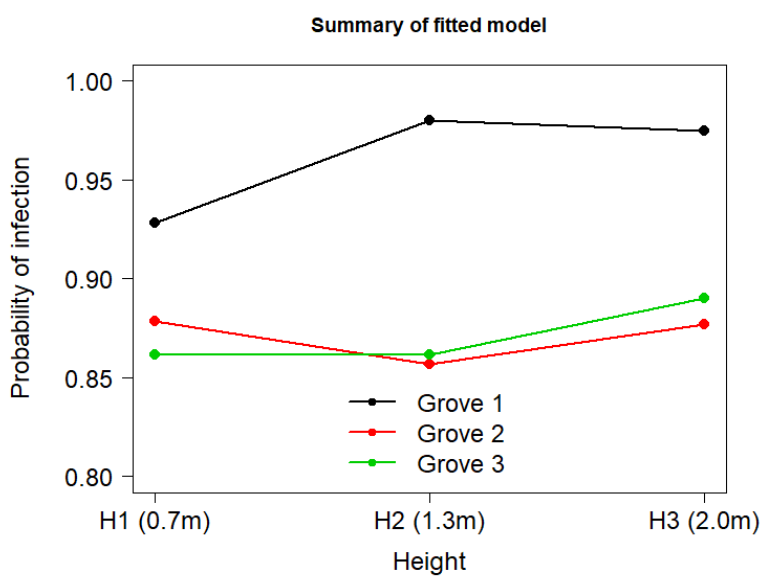

